\title{
Identification of Bacteria in Two Food Waste Black Soldier Fly Larvae Rearing Residues
}

\author{
Moritz Gold 1,2, Fabienne von Allmen ${ }^{1,2}$, Christian Zurbrügg ${ }^{2}$, Jibin Zhang ${ }^{3}$ and \\ Alexander Mathys ${ }^{1 *}$ \\ 1 Sustainable Food Processing Laboratory, Department of Health Science and Technology, Institute of Food, Nutrition \\ and Health, ETH Zürich, Zurich, Switzerland, ${ }^{2}$ Department Sanitation, Water and Solid Waste for Development (Sandec), \\ Eawag: Swiss Federal Institute of Aquatic Science and Technology, Dübendorf, Switzerland, ${ }^{3}$ State Key Laboratory \\ of Agricultural Microbiology, National Engineering Research Center of Microbial Pesticides, College of Life Science \\ and Technology, Huazhong Agricultural University, Wuhan, China
}

OPEN ACCESS

Edited by: Jørgen Eilenberg, University of Copenhagen, Denmark

Reviewed by: Panagiota Stathopoulou, University of Patras, Greece

Nikolaos Remmas, Democritus University of Thrace,

Greece

*Correspondence: Alexander Mathys alexander.mathys@hest.ethz.ch

Specialty section:

This article was submitted to

Food Microbiology,

a section of the journal

Frontiers in Microbiology

Received: 13 July 2020

Accepted: 26 October 2020

Published: 23 November 2020

Citation:

Gold $M$, von Allmen F,

Zurbrügg C, Zhang J and Mathys $A$ (2020) Identification of Bacteria in Two Food Waste Black Soldier Fly Larvae

Rearing Residues.

Front. Microbiol. 11:582867. doi: 10.3389/fmicb.2020.582867
Significant economic, environmental, and social impacts are associated with the avoidable disposal of foods worldwide. Mass-rearing of black soldier fly (Hermetia illucens) larvae using organic wastes and food- and agro-industry side products is promising for recycling resources within the food system. One current challenge of this approach is ensuring a reliable and high conversion performance of larvae with inherently variable substrates. Research has been devoted to increasing rearing performance by optimizing substrate nutrient contents and ratios, while the potential of the substrate and larval gut microbiota to increase rearing performance remains untapped. Since previous research has focused on gut microbiota, here, we describe bacterial dynamics in the residue (i.e., the mixture of frass and substrate) of black soldier fly larvae reared on two food wastes (i.e., canteen and household waste). To identify members of the substrate and residue microbiota, potentially associated with rearing performance, bacterial dynamics were also studied in the canteen waste without larvae, and after inactivation by irradiation of the initial microbiota in canteen waste. The food waste substrates had similar microbiota; both were dominated by common lactic acid bacteria. Inactivation of the canteen waste microbiota, which was dominated by Leuconostoc, Bacillus, and Staphylococcus, decreased the levels of all rearing performance indicators by $31-46 \%$ relative to canteen waste with the native microbiota. In both food waste substrates, larval rearing decreased the bacterial richness and changed the physicochemical residue properties and composition over the rearing period of 12 days, and typical members of the larval intestinal microbiota (i.e., Providencia, Dysgonomonas, Morganella, and Proteus) became more abundant, suggesting their transfer into the residue through excretions. Future studies should isolate members of these taxa and elucidate their true potential to influence black soldier fly mass-rearing performance. 


\section{INTRODUCTION}

Significant economic, environmental, and social impacts are associated with the avoidable disposal of foods worldwide (Gustavsson et al., 2011; Papargyropoulou et al., 2014; Chen et al., 2020). Measures to reduce food loss and waste amount exceeding 1.3 billion tons per year (Gustavsson et al., 2011) include avoiding surplus food production, followed by redistribution and reuse of surplus foods (Papargyropoulou et al., 2014). Once produced, food loss and wastes should be recycled by using them as animal feed (Dou et al., 2018) or compost (Li et al., 2013), and extraction of energy should be the least preferred approach (Papargyropoulou et al., 2014). In recent years, mass rearing of the black soldier fly (Hermetia illucens L., Diptera: Stratiomyidae) larvae (BSFL) has emerged as an additional solution for food waste recycling (Gold et al., 2018; Zurbrügg et al., 2018; Berggren et al., 2019; Varelas, 2019). BSFL convert a range of organic wastes (e.g., food waste, animal manure) and food- and agro-industry side products (e.g., breweries, food processing industry) (Nyakeri et al., 2017; Barragán-Fonseca et al., 2018; Lalander et al., 2019; Gold et al., 2020a) into larval biomass and a compost-like residue (i.e., mixture of frass and substrate). The larval biomass is rich in proteins and lipids, and thus, serves as a raw material for various applications within the food system, such as proteins and lipids in feeds for pets (Bosch et al., 2014) and livestock (e.g., fish, poultry, swine) (Barragán-Fonseca et al., 2017; Wang and Shelomi, 2017), and processing of the larval exoskeleton into chitosan (Hahn et al., 2019). Next to this recycling of waste nutrients, according to circular economy principles (Cappellozza et al., 2019), waste treatment by BSFL (Ermolaev et al., 2019; Mertenat et al., 2019; Pang et al., 2020) and animal feed products (Smetana et al., 2016, 2019) with BSFL can have lower environmental impact than the status quo (i.e., composting and commercial feed ingredients such as fish meal).

One current challenge for BSFL rearing is to obtain reliable and high rearing performance (e.g., > $200 \mathrm{mg}$ for harvested BSFL) (Gold et al., 2018). Researchers have previously improved rearing performance by optimizing substrate nutrient contents and ratios (Nyakeri et al., 2017; Barragán-Fonseca et al., 2018; Gold et al., 2020a), however, few studies exist regarding the manifold roles in which BSFL-associated microbiota may influence rearing performance (De Smet et al., 2018). BSFL guts, rearing substrates and residues (i.e., the mixture of frass and substrate) all have rich and diverse microbiomes (Bruno et al., 2019; Klammsteiner et al., 2020) varying due to different biotic (e.g., initial rearing substrate microbiome) and abiotic (e.g., temperature) factors among rearing systems (Wynants et al., 2019; Raimondi et al., 2020). Similar to many insects (Douglas, 2009; Engel and Moran, 2013; Lee and Brey, 2013), Dipteran larvae such as those of Drosophila melanogaster (Diptera: Drosophilidae) and Musca domestica (Diptera: Muscidae) engage in complex interactions with their gut microbiota, as these influence larval immunity (Broderick and Lemaitre, 2012) and metabolism (Shin et al., 2016), growth signaling (Storelli et al., 2011), and nutrient provision (Zurek and Nayduch, 2016). Microbiota associated with BSFL may have similar functions (Ao et al., 2020) considering their similar ecological niche and phylogenetic order (Gold et al., 2018; Zhan et al., 2020). Identification and manipulation (e.g., by addition of bacterial mixtures) of microbiota in BSFL rearing is an additional promising approach to increase rearing performance, next to the optimization of substrate nutrient contents and ratios.

Members of the BSFL gut microbiota (e.g., Bacillus natto, Bacillus subtilis, Lactobacillus buchneri, and Kocuria marina) can increase performance when added to rearing substrates (Yu et al., 2011; Xiao et al., 2018; Rehman et al., 2019; Somroo et al., 2019; Mazza et al., 2020). Members of the substrate and residue microbiota are an additional yet unexplored pool of potentially beneficial bacteria. Fly larvae may support and sustain certain microbiota in the substrate and residue to favor decomposition and digestibility (Zhao et al., 2017) and thus larval development (Storelli et al., 2018) and also protect from other insects and microbes competing for the same resources (Bernard et al., 2020). Bacterial candidates associated with rearing performance could be identified by studying microbiota throughout the rearing time in the substrate and rearing residue. For BSFL, previous studies have typically only determined the bacterial community in the initial substrate as well as the final residue. Jiang et al. (2019) were the first to determine bacterial community dynamics throughout one rearing cycle and found that BSFL rearing affects and alters the substrate bacterial community over time to increase the capacity to decompose the substrate. Lalander et al. (2013) and Erickson et al. (2004) also reported a reduction in certain bacteria during BSFL rearing, and Cai et al. (2018) and Liu et al. (2020) reported a reduction in antibiotic resistance genes in bacteria. These results contradict the findings of Bruno et al. (2019), who did not identify a significant influence of BSFL on substrate microbiota during rearing. Changing the bacterial community in the rearing substrate may also be beneficial for rearing of insects for food and feed applications, when considering that the substrate microbial community may include human and animal pathogens (e.g., Bacillus cereus and Enterococcus faecalis) (Lalander et al., 2013; Van der Fels-Klerx et al., 2018; Wynants et al., 2019).

The aim of this study was to identify groups of bacteria potentially associated with BSFL residues and the rearing performance. We assessed the bacterial community dynamics when using two food waste substrates during BSFL rearing. We also studied the bacterial community dynamics in food waste after inactivation by irradiation of the initial microbiota in food waste with and without BSFL. We hypothesized that an inactivation of the initial microbial community in the substrate should decrease rearing performance, revealing that some important bacteria are associated with rearing performance. In addition, we hypothesized that certain groups of bacteria become more abundant during BSFL rearing in comparison to controls without larvae.

\section{MATERIALS AND METHODS}

\section{Food Waste Substrates}

Two types of food waste were collected in containers treated with $70 \%$ ethanol. Canteen waste included a mixture of discarded pasta, meat, fish, bread, and vegetables from the 
Polyterrasse canteen at ETH Zürich in Switzerland. Household waste included discarded fruit peels, vegetables, eggs, bread, herbs, and food leftovers collected from a household organic waste bin in Zürich. Each collected substrate mixture was homogenized with a kitchen blender to mimic typical waste processing before BSFL rearing (Dortmans et al., 2017). Pictures of the fresh and homogenized rearing substrates are included in Supplementary Table 1. Following homogenization, the rearing substrates were stored at $4^{\circ} \mathrm{C}$ for $48 \mathrm{~h}$. During this storage time, part of the canteen waste was sterilized with a high-energy electron beam. This substrate was fed to BSFL in parallel to the non-sterile food wastes to assess the influence of the loss of the initial substrate microbiota on rearing performance and bacterial dynamics. Irradiation was completed by a commercial provider (Leoni Studer AG, Däniken, Switzerland) with a $10 \mathrm{MeV}$ electron beam (Rhodotron TT300, IBA Corp., Louvain-la-Neuve, Belgium) at a dose of $32 \mathrm{kGy}$ in accordance with the ISO 11137-3:2017 standard [International Organization for Standardization (ISO), 2017]. These treatment conditions produced sterile substrates without microbial growth (Gold et al., 2020b).

Since substrate composition influences microbial communities and BSFL rearing performance, substrate gross nutrient composition, $\mathrm{pH}$, and moisture content were determined using standard procedures described in detail in Gold et al. (2020a). The $\mathrm{pH}$ was measured with a portable meter and the $\mathrm{pH}$ probe HQ40d (Hach Lange $\mathrm{GmbH}$, Rheineck, Switzerland). Moisture and organic matter were determined using an automatic thermogravimetric instrument (TGA701, Leco, St. Joseph, MI, United States). Nitrogen content was determined using a $\mathrm{C} / \mathrm{N}$ analyzer (Type TruMac $\mathrm{CN}$, Leco). Glucose (D-Glucose GOPOD K-GLUC, Megazyme, Wicklow, Ireland) and starch (Total Starch Assay K-TSTA, Megazyme), and fructose (Available Carbohydrates K-ACHDF, Megazyme) were determined using commercial enzyme assays. For fructose determination, absorbance differences of $>0.07$ were used instead of $>0.1$, as recommended by the manufacturer. Neutral and acid detergent fibers were assessed using a fiber bag system (Fibretherm, Gerhardt Analytical Systems, Königswinter, Germany). Lipids were analyzed by Eurofins Scientific, Schönenwerd, Switzerland, according to Regulation (EC) No 152/2009 (European Commission, 2009). Protein was estimated by multiplying the nitrogen results with 5.4 (based on results for meat, fish, cereals, and vegetables) (Mariotti et al., 2008), and the caloric content was estimated by multiplying the mean lipid, non-fiber carbohydrate, and protein results with their gross caloric content of 9.4, 5.4, and $4.1 \mathrm{kcal} / \mathrm{g}$, respectively (Merrill, 1973; Wu, 2016). Hemicellulose content was determined as the difference between the neutral and acid detergent fibers. The sum of glucose, fructose, and starch was assumed to reflect the total non-fiber carbohydrate content.

\section{Fly Larva Rearing}

BSFL were reared on homogenized food waste substrates using the following experimental setup. BSFL were obtained from a colony operated at Eawag (Dübendorf, Switzerland) since 2017, based on the protocol of Dortmans et al. (2017). The hatched larvae were fed ad libitum with poultry feed (UFA 625, UFA AG, Herzogenbuchsee, Switzerland) for 7-9 days to a weight of $0.5 \mathrm{mg}$ dry mass (DM)/larva. Thereafter, larvae were manually separated from the poultry feed residue and 12 replicates with approximately 200 larvae per replicate were prepared for each treatment. To eliminate possible contaminations by airborne microbes, cross-contamination between substrates, and contamination with human microbes during rearing, larvae were reared in an one-time-feeding bench-scale batch experiment. Larvae were placed in sterile plastic containers (diameter: $100 \mathrm{~mm}$, height: $80 \mathrm{~mm})(\mathrm{O} 118 / 80$, Eco2 NV, Ophasselt, Belgium) with substrates at a feeding rate of $22 \mathrm{mg}$ DM/larva per day for 12 days, resulting in a larval density of 2.5 larvae $/ \mathrm{cm}^{2}$. Plastic containers were covered with lids (OD118 Filter XL, Eco2 $\mathrm{NV}$, Ophasselt) permitting air flow, while being impermeable to microbes. Containers were placed in a random order in a climate chamber (HPP 260, Memmert $\mathrm{GmbH}$, Büchenbach, Germany), providing a microclimate of $28^{\circ} \mathrm{C}$ and $70 \%$ relative humidity. Temperature was automatically recorded every $10 \mathrm{~min}$ in the substrate/residue of one replicate per treatment (DS1922L iButton, Maxim Integrated, San Jose, CA, United States).

For each treatment, every 3 days, for a total of 12 days, three containers were removed from the climate chamber. One residue sample was collected per removed container to determine the physicochemical (see section "Physicochemical Properties and Composition of the Residue") and microbial parameters in the residue (see section "Microbial Counts and Bacterial Communities"). Larvae were manually separated from the residue, cleaned with tap water, and dried with paper towels. Larvae were counted, weighed, freeze-dried and then stored at $4^{\circ} \mathrm{C}$ before larval protein content (see section "Microbial Counts and Bacterial Communities") measurement. Residue samples were analyzed for water activity and $\mathrm{pH}$, thereafter freeze-dried and stored to later measure other physicochemical parameters. Weight loss in larvae and residue samples during freeze drying was used to correct all results for moisture content. All manipulations with rearing containers and collection of substrate/residue samples for microbial parameters were performed using sterile techniques under a laminar flow cabinet.

\section{Controls With No Larvae}

Sterile and non-sterile canteen waste without larvae underwent experimental and environmental conditions identical to those used for BSFL rearing. After 12 days in sterile containers in the climate chamber, samples were collected and processed in the same way as the rearing residue samples.

\section{Physicochemical Properties and Composition of the Residue}

Changes in the residue composition were measured through physicochemical parameters which are relevant for microbial growth. Portable meters were used to measure water activity (HygroPalm23-AW, Rotronic, Bassersdorf, Switzerland) and $\mathrm{pH}$ (HQ40d, Hach Lange $\mathrm{GmbH}$ ) in the fresh residue samples. A thermogravimetric instrument (TGA-701, Leco) and a C/N analyzer (Type TruMac CN, 
Leco) were used to measure moisture and organic matter, and carbon and nitrogen on the freeze-dried residue samples, respectively.

\section{Rearing Performance}

Residue and larval dry weights as well as larval protein content were used to calculate typical rearing performance indicators per replicate. Larval weight, bioconversion rate, and waste reduction were calculated according to Gold et al. (2020a). The total larval protein per biological replicate (which had 200 larvae) was calculated using equation 1 .

$$
\begin{aligned}
& \underset{\text { Total larval }}{\text { protein }}\left(\frac{\mathrm{g} \text { DM protein }}{\text { replicate }}\right)=\text { larval weight }\left(\frac{\mathrm{g} \mathrm{DM}}{\text { larva }}\right) \mathrm{x} \\
& \text { larval protein content }\left(\frac{\mathrm{g} \text { DM protein }}{100 \mathrm{~g} \text { DM }}\right) \times \frac{200 \text { larvae }}{\text { replicate }}
\end{aligned}
$$

Each larval protein content was estimated as nitrogen content $\times 4.67$, as proposed by Janssen et al. (2017). Nitrogen was measured on freeze-dried samples using a $\mathrm{C} / \mathrm{N}$ analyzer (Type TruMac CN, Leco) and corrected for residual moisture with thermogravimetric determinator (TGA-701, Leco).

\section{Microbial Counts and Bacterial Communities}

Culturable microbial counts (i.e., CFU: colony forming units) in the substrate and residue were estimated using plate counts from a dilution series. Microbes were extracted from samples $(10 \mathrm{~g})$ by $2 \mathrm{~min}$ Stomacher treatment in a medium for recovery of organisms (Difco Maximum Recovery Diluent, BD Diagnostics, Le Pont-de-Claix, France). For each sample, $50 \mu \mathrm{L}$ of the dilution series were spread in duplicate on Petri dishes (diameter: $90 \mathrm{~mm}$ ) divided into four quadrants. Since we partially recorded colonies within the representative range of 20-250 for different dilutions and replicate plates, counts in the Stomacher-homogenate were calculated using equation 2 (Maturin and Peeler, 2001)

$$
\frac{C F U}{m L}=\frac{\sum \mathrm{c}}{\mathrm{V} \times\left(1 \mathrm{n}_{1}+0.1 \mathrm{n}_{2}\right) \times \mathrm{d}}
$$

where $\Sigma c$ is the number of colonies on all plates, $V$ is the volume added to each plate $(0.05 \mathrm{~mL}), \mathrm{n}_{\mathrm{i}}$ is the number of quadrants counted of the $i_{\text {th }}$ dilution, and $d$ is the dilution. Total viable counts (TVC) were determined using standard agar $(15 \mathrm{~g} / \mathrm{L}$ Agar, VWR International, Leuven, Belgium; 30 g/L Tryptic Soy Broth No. 2, Sigma Aldrich GmbH, Buchs, Switzerland), lactic acid bacteria (LAB) on De Man, Rogosa, and Sharpe Agar (MRS, VWR International), and fungi on Dichloran Rose Bengal Chloramphenicol Agar (DRBC, Sigma Aldrich GmbH) after incubation at $30^{\circ} \mathrm{C}$ for 20 to $48 \mathrm{~h}$. Media and incubation conditions were selected based on the manufacturer's directions and previous work by Wynants et al. (2019).

The bacterial community was determined by high-throughput 16S rRNA gene sequencing using the MiSeq Illumina platform. Total genomic DNA was extracted from $0.2 \mathrm{~g}$ of substrate (in single) or residue (single to quadruplicate per substrate and sampling day, see Figures 1, 2) sample using the DNeasy PowerSoil Kit (QIAGEN, Hilden, Germany) with one modification. To enhance DNA extraction, three sterile metal beads (diameter: $3 \mathrm{~mm}$; Uiker AG, Freienbach, Switzerland) were added to each PowerBead Tube with the lysis buffer and homogenized with a Bead Ruptor (Omni International, Kennesaw GA, United States; speed 5.5, $2 \times 20 \mathrm{~s}$ with $30 \mathrm{~s}$ break between rounds). Purity (NanoDrop ND 1000 Spectrophotometer, Thermo Scientific, Wilmington MA, United States) and concentration Qubit dsDNA HR Assay Kit on a Spark $10 \mathrm{M}$ microplate reader (Tecan, Männedorf, Switzerland) of the extracted DNA was determined. Library preparation followed a two-step protocol. Limited-cycle PCR was conducted in a $25 \mu \mathrm{L}$ reaction volume using KAPA HiFi HotStart ReadyMix (12.5 $\mu \mathrm{L}$ ) (Kapa Biosystems, Wilmington, MA, United States), template DNA $(5 \mu \mathrm{L})$, forward and reverse primer $(0.75 \mu \mathrm{L} ; 0.3 \mathrm{mM}$ each), and molecular-grade water $(6 \mu \mathrm{L})$. All primers included a hexanucleotide barcode and Illumina adapters (Illumina Inc., San Diego, CA, United States). The prokaryotic V3-V4 hypervariable region was amplified in triplicate using the primer pair $341 \mathrm{~F}$ (5' - CCT ACG GGN GGC WGC AG 3') and 806R (5'- GGA CTA CNV GGG TWT CTA AT $\left.-3^{\prime}\right)$. PCR conditions were an initial denaturation at $95^{\circ} \mathrm{C}$ for $300 \mathrm{~s}, 1$ cycle at $98^{\circ} \mathrm{C}$ for $60 \mathrm{~s}, 26$ cycles of $98^{\circ} \mathrm{C}$ for $20 \mathrm{~s}, 51^{\circ} \mathrm{C}$ for $20 \mathrm{~s}$, and $72^{\circ} \mathrm{C}$ for $12 \mathrm{~s}$, and a final extension at $72^{\circ} \mathrm{C}$ for $120 \mathrm{~s}$ (Hugerth et al., 2014). Negative controls were run by replacing template DNA with molecular grade water. A positive control was run by replacing template DNA with a known mixture of bacterial DNA (i.e., mock sample). Products from the first PCR were pooled, cleaned using solidphase reversible immobilization beads (ETH Zürich Genetic Diversity Center, Zurich, Switzerland) and used as a template for the second PCR to attach dual indices using the Nextera $\mathrm{XT}$ Index Kit v2 (Illumina Inc.). Index PCR included the first PCR product $(2 \mu \mathrm{L})$, KAPA HiFi HotStart ReadyMix $(10 \mu \mathrm{L})$, molecular grade water $(4 \mu \mathrm{L})$, and Nextera indexing primers $(2 \mu \mathrm{L})$. PCR conditions were an initial denaturation at $95^{\circ} \mathrm{C}$ for $180 \mathrm{~s}, 10$ cycles at $95^{\circ} \mathrm{C}$ for $30 \mathrm{~s}, 55^{\circ} \mathrm{C}$ for $30 \mathrm{~s}$, and $72^{\circ} \mathrm{C}$ for $30 \mathrm{~s}$, and a final extension at $72^{\circ} \mathrm{C}$ for $300 \mathrm{~s}$. Index PCR products were cleaned and DNA concentration was determined using the High Sensitivity D1000 Kit on a 2200 TapeStation (Agilent Technologies Inc., Santa Clara, CA, United States). Cleaned PCR products were pooled equimolar to a library concentration of $2 \mathrm{nM}$. The concentration and purity of the pooled library were controlled using a Qubit Fluorometer (Invitrogen Q32857, Carlsbad, CA, United States) and the TapeStation, respectively. Paired-end sequencing was performed using $19 \mathrm{pM}$ of the prepared library in a single MiSeq $2 \times 300$ bp flow cell, using the MiSeq Reagent Kit v3 and a 10\% PhiX concentration according to the manufacturer's directions (Illumina Inc.).

\section{Bioinformatics}

Initial quality control of the sequencing data was conducted using FastQC (version 0.11.2). Subsequent bioinformatics data preparation included trimming of read ends with USEARCH (version 11.0.667) and merging of pairs into amplicons with FLASH (Magoč and Salzberg, 2011). Following removal of primer 

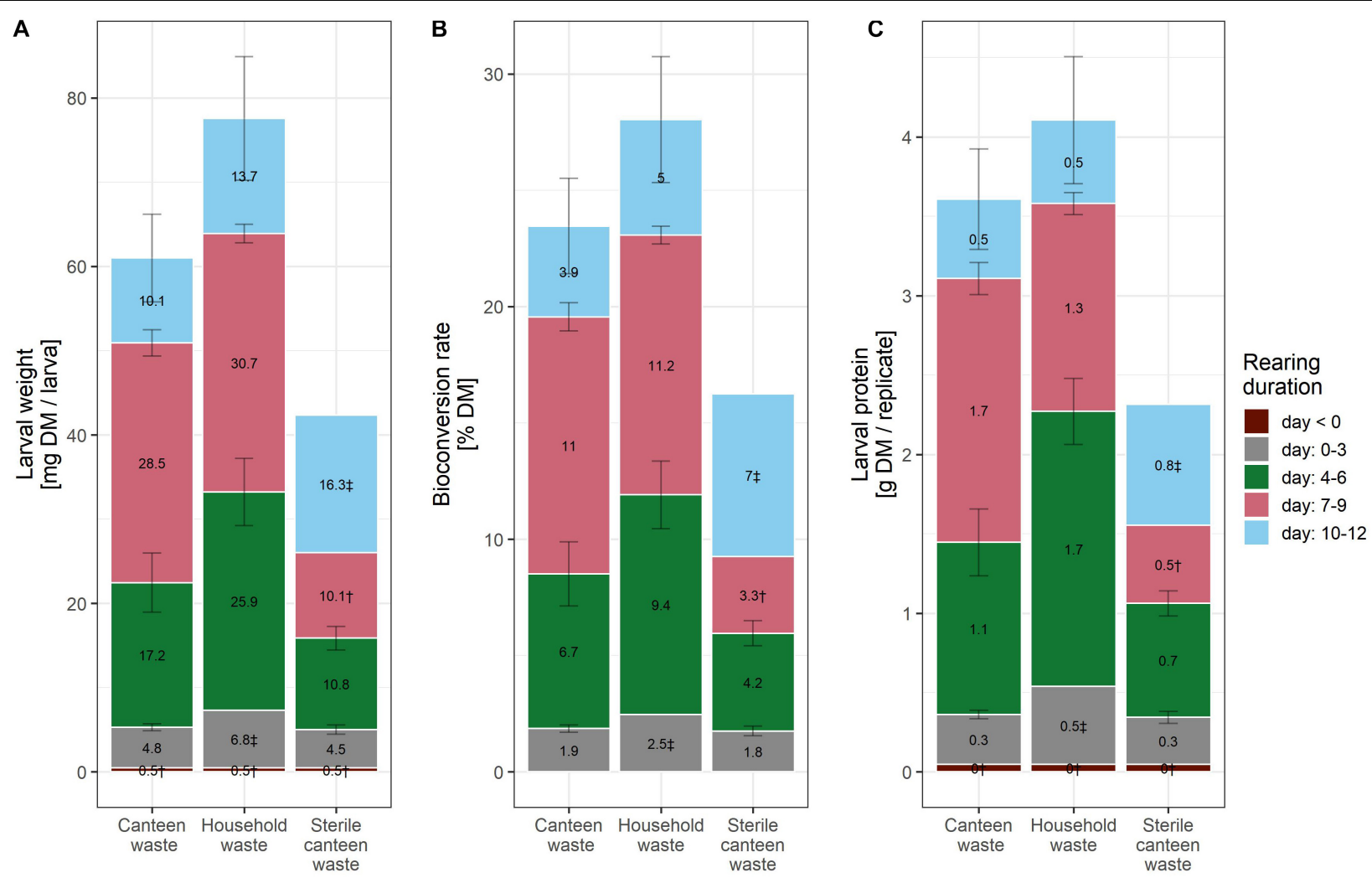

FIGURE 1 | Rearing performance of BSFL on canteen and household food waste. Bar plot of larval weight (A), bioconversion rate (B), and larval protein per replicate (C). The bar plot label shows the mean increase in the levels of the performance indicator between the measurement days. ${ }^{\dagger}(n=1)$ and ${ }^{*}(n=2)$ indicate results with fewer than three biological replicates.

sites with USEARCH, quality-filtering was performed with the PRINSEQ-lite (version 0.20.4) (Schmieder and Edwards, 2011). The resulting high-quality reads were de-noised and clustered into zero-radius operational taxonomic units (ZOTUs) using the UNOISE3 algorithm (Edgar, 2016b). The taxonomic origin of each ZOTU was determined with the SINTAX algorithm (version 11.0.667) (Edgar, 2016a) in USEARCH using Silva 16S (V128) as the reference database. Taxonomic assignments were considered reliable when bootstrap confidence values exceeded 0.85 .

\section{Downstream Data Analyses}

Data were analyzed using $\mathrm{R}$ version 312 3.6.2 (R Core Team, 2020). Rare ZOTUs with less than 10 total counts and samples with less than 2000 reads (i.e., the highest number of reads in the control samples) were removed before downstream analyses. ZOTUs belonging to the phylum Cyanobacteria and to the family Mitochondria were also removed, as they likely belonged to eukaryotic 16S rRNA (Michelou et al., 2013), given the plant-based nature of the rearing substrates. We abstained from statistical analyses among sampling days for all parameters due to the small number of replicates $(n=1-3)$. Instead, we compared the results visually or using the mean and standard deviation (when $n>2$, difference between values for $n=2$ ). The mean and standard deviation were calculated for rearing performance indicators, physicochemical residue parameters, and microbial counts. Differences in rearing performance indicators between measurement days were calculated by subtracting the mean values. Pearson correlation coefficients $(p<0.01)$ were calculated following visual assessment of normality (see Supplementary Figures 2, 3) to identify linear dependencies between rearing performance indicators and the physicochemical residue composition.

Heat maps at the phylum and genus levels were produced in ampvis2 (Andersen et al., 2018) after conversion of reads into percent abundance per sample. The same package was used to identify shared ZOTUs between samples with Venn diagrams (frequency cutoff $>80 \%$ and abundance cutoff $>0.01 \%$ ). Alpha diversity (i.e., observed richness, Chao1, Shannon index, and Simpson Index) and beta diversity [i.e., non-metric multidimensional scaling (NMDS)] were calculated in phyloseq (McMurdie and Holmes, 2013). NMDS was used to illustrate the bacterial dynamics of ZOTUs that accounted for more than $1 \%$ of relative abundance in all samples using weighted UniFrac distance to account for phylogenic distances between ZOTUs. Distance-based redundancy analysis (dbRDA) was performed on the same data in vegan (Oksanen et al., 2019) with the capscale function using the Bray-Curtis Dissimilarity matrix to determine correlations between physicochemical residue properties and composition, rearing performance, and bacterial community 

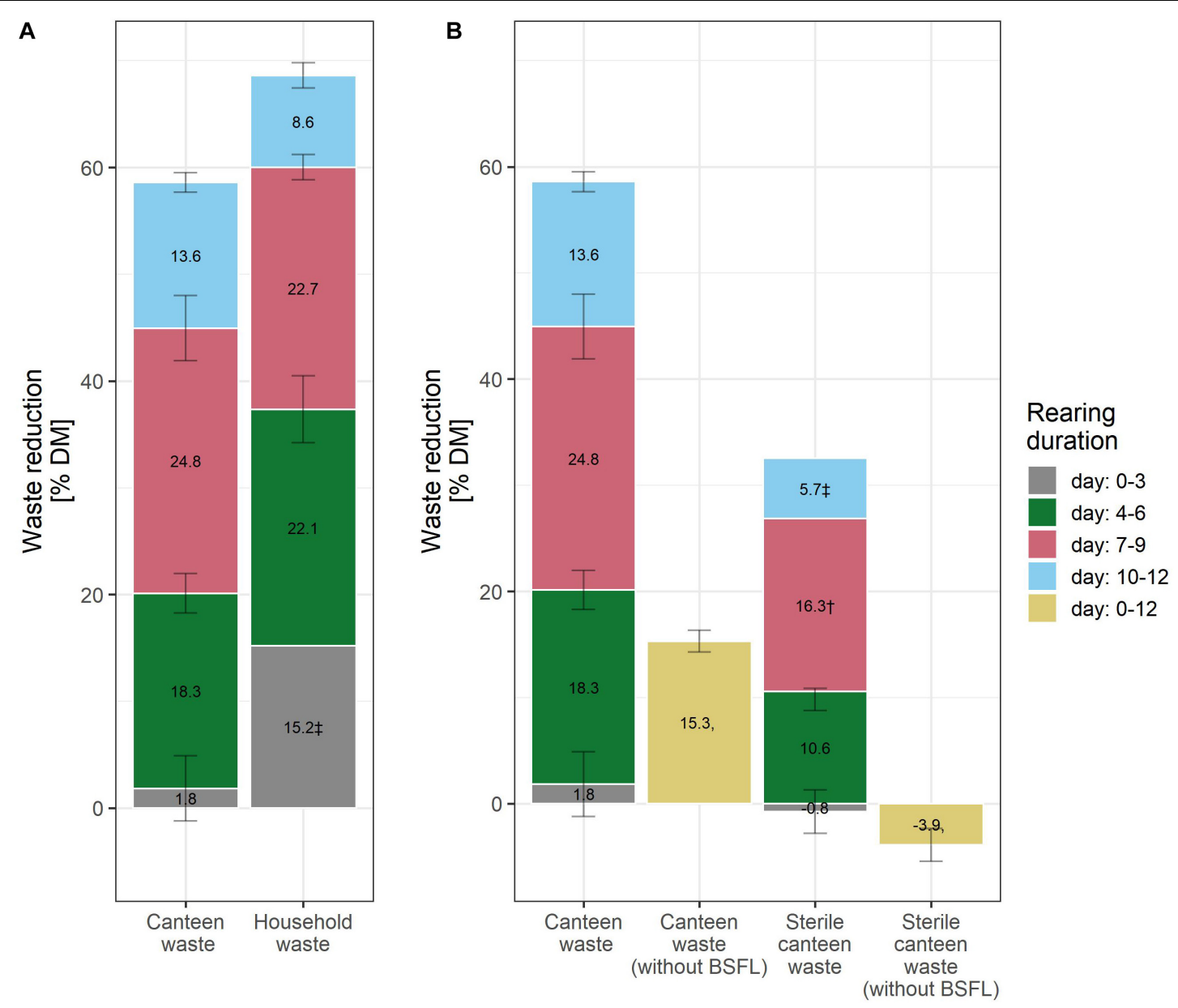

FIGURE 2 | Waste reduction during BSFL rearing with canteen and household food waste (A), and on canteen waste without larvae, and sterile canteen waste with and without larvae (B). The bar plot label shows the mean increase in the levels of the performance indicators between the measurement days. ${ }^{\dagger}(n=1)$ and ${ }^{\ddagger}(n=2)$ indicate results with fewer than three biological replicates.

dynamics. Prior to analysis, parameters with co-linearity were excluded from the data with a Pearson correlation matrix (see Supplementary Figure 1) and variance inflation factors (VIF) using the $u s d m$ function. A VIF value $>5$ indicated multicollinearity. The remaining parameters were scaled and centered. The significance of the model and the correlation of each parameter with the bacterial community was determined by the permutation test (1000 iterations) with a $p$-value $<0.05$, denoting significance.

\section{RESULTS}

\section{Waste Nutrient Composition}

The household and canteen waste rearing substrates had similar protein contents, but canteen waste was richer in hemicellulose, lipids, and non-fiber carbohydrates (Table 1). Household waste had more cellulose and lignin, as well as glucose and fructose, that was almost absent in the canteen waste.

\section{Rearing Performance}

Considering the mean and standard deviation, the bioconversion rate and larval protein were similar between the two rearing substrates (Figures 1B,C), but larval weight (Figure 1A) and waste reduction (Figure 2A) were higher for household than for canteen waste. Following 12 days of rearing, mean (standard deviation) bioconversion rate and larval protein were $28.0(2.7) \% \quad \mathrm{DM}$ and $4.1(0.4) \mathrm{g}$ protein/replicate for household waste, and 23.5 (2.1)\% DM and $3.6(0.3)$ $\mathrm{g}$ protein/replicate for canteen waste. Larval weight and waste reduction were higher for household than for canteen waste: 77.6 (7.3) $\mathrm{mg} \mathrm{DM}$ and 68.6 (1.2)\% DM for household waste, and 61.0 (5.2) $\mathrm{mg} \mathrm{DM}$ and 58.6 (1.0)\% DM for canteen waste.

Inactivation of the initial canteen waste microbiota by irradiation reduced rearing performance (Figures 1, 2). In rearing with sterile canteen waste, larval weight, bioconversion rate, larval protein levels, and waste reduction were reduced by $18.7 \mathrm{mg} \mathrm{DM}, 7.3 \% \mathrm{DM}, 1.3 \mathrm{~g}$ protein/replicate, and $26.8 \%$ DM, respectively. Without larvae, 15.3 (1.0)\% DM was lost from 


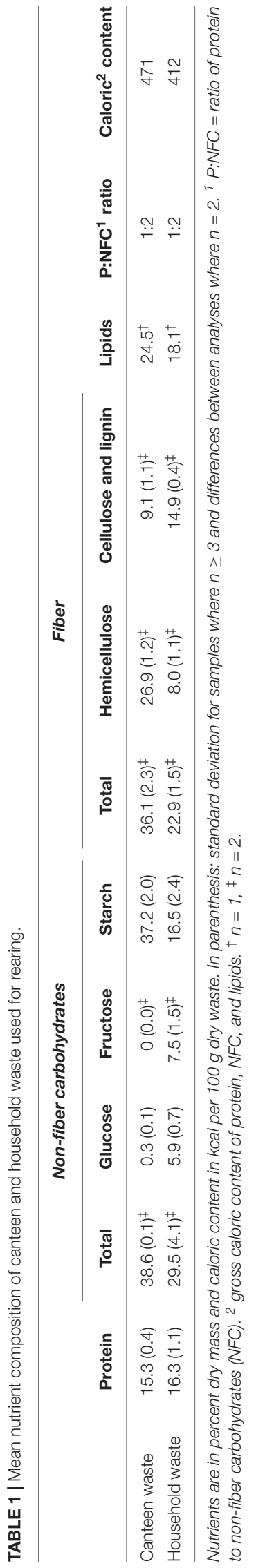

canteen waste, and $-3.9(1.6) \% \mathrm{DM}$ was lost from sterile canteen waste (Figure 2B).

\section{Physicochemical Residue Composition}

Rearing performance indicators were positively correlated with residue moisture content $(r=0.75-0.86, p<0.01)$ and $\mathrm{pH}(r=0.76-0.81, p<0.01)$ (Table 2). Moisture and nitrogen content (Table 2) increased throughout the rearing experiment in the canteen and household waste residue in comparison to the substrates. The residue $\mathrm{pH}$ decreased from the substrate value in the first half of rearing, and then increased above the initial substrate value in the second half of rearing. Residue organic matter had different trends for the two rearing substrates. It decreased from the value in the household waste, but not in the canteen waste substrate. Values for carbon (range: 49.2-56.0\% DM), water activity (range: $0.95-0.99$ ), and temperature (range: $27.5-29.9^{\circ} \mathrm{C}$ ) showed low variability throughout the rearing experiment from the initial value ( $\leq \pm 5 \%$, see Supplementary Table 2$)$. The residue composition changed much less when the initial canteen waste microbiota was inactivated. Except for the residue moisture content and the carbon to nitrogen ratio, the residue composition was $\leq \pm 5 \%$ relative to the initial value in the substrate.

\section{Microbial Dynamics Canteen and Household Waste Rearing Substrates}

Canteen and household waste had similar counts of TVC, LAB, and fungi (Table 2). Throughout the rearing experiment, residue microbial counts deviated by $\pm 1-3 \log _{10}$ CFU/g from the counts in the substrate. At the end of the rearing experiment, TVC in the canteen waste residue was $1 \log _{10}$ CFU/g higher and in the household waste residue $1 \log _{10} \mathrm{CFU} / \mathrm{g}$ lower than that in the substrate. $\mathrm{LAB}$ counts decreased by $1-2 \log _{10} \mathrm{CFU} / \mathrm{g}$ and fungal counts increased by $2-3 \log _{10} \mathrm{CFU} / \mathrm{g}$ in the residue in comparison to the counts in the substrate.

Considering all 45 samples, gene sequencing using DNA produced a total of 1,783,860 reads, with an average of 44,597 reads/sample, and a total of 275 ZOTUs. Rarefaction curves (see Supplementary Figure 4) demonstrate that samples were sequenced to an extent sufficient to approximate true diversity. The canteen waste and household waste bacterial community consisted of 119 and 125 ZOTUs, respectively (Table 2). Canteen waste was dominated by a few genera of Firmicutes, and household waste by Firmicutes and Proteobacteria (Figure 3). Dominant genera were Leuconostoc, Bacillus, Staphylococcus in the canteen waste and Leuconostoc, Weissella, Pseudomonas, Oxalobacteraceae, and Lactococcus in the household waste. Sixty two percent of the relative abundance of the two wastes was due to 28 shared ZOTUs, while 49 ZOTUs were unique to canteen waste and 34 ZOTUs were unique to household waste (see Venn diagram in Supplementary Figure 5). Unique high-abundance (>10\%) species were from Pseudomonas and Oxalobacteraceae in household waste and Staphylococcus and Bacillus in canteen waste.

The results for the bacterial community alpha and beta diversity demonstrated that the addition of BSFL to the substrates 
TABLE 2 | Physicochemical properties, composition, microbial counts, and bacterial community alpha diversity (i.e., richness and diversity) in the substrates and residues.

\begin{tabular}{|c|c|c|c|c|c|c|c|c|c|c|c|c|c|}
\hline Substrate & Day & $\begin{array}{c}\text { Moisture } \\
\text { content }\end{array}$ & $\mathrm{pH}$ & Nitrogen & $\mathrm{C} / \mathrm{N}$ & $\begin{array}{l}\text { Organic } \\
\text { matter }\end{array}$ & TVC & LAB & Fungi & $\begin{array}{l}\text { Observed } \\
\text { richness }\end{array}$ & Chao 1 & $\begin{array}{l}\text { Shannon } \\
\text { Index }\end{array}$ & $\begin{array}{l}\text { Simpson's } \\
\text { Index }\end{array}$ \\
\hline & & $\%$ & - & $\% \mathrm{DM}$ & - & $\% \mathrm{DM}$ & $\log _{10} / g$ & $\log _{10} / g$ & $\log _{10} / g$ & - & - & - & - \\
\hline \multicolumn{14}{|l|}{ BSFL rearing } \\
\hline \multirow[t]{5}{*}{ Canteen waste } & 0 & $69.5(0.2)^{\ddagger}$ & $4.4(0.0)^{\ddagger}$ & $2.9^{\dagger}$ & $19.3^{\dagger}$ & $95.9(0.0)^{\ddagger}$ & $9.2(0.2)$ & $9.2^{+}$ & $5.2(0.5)$ & $119^{\dagger}$ & $140^{\dagger}$ & $2.4^{+}$ & $0.8^{\dagger}$ \\
\hline & 3 & $69.0(1.0)$ & $3.8(0.0)$ & $3.5^{\dagger}$ & $15.2^{\dagger}$ & $95.8(0.1)$ & $8.4(0.2)$ & $8.4(0.2)$ & $6.8(0.0)$ & $113(14)$ & $148(45)$ & $2.4(0.2)$ & $0.8(0.0)$ \\
\hline & 6 & $71.8(0.3)$ & $3.7(0.1)$ & $3.4(0.3)$ & $16.2(1.4)$ & $95.2(0.2)$ & $7.7(0.0)$ & $7.7(0.1)$ & $6.7(0.1)$ & $92(5)$ & $103(10)$ & $2.3(0.1)$ & $0.8(0.0)$ \\
\hline & 9 & $77.4(1.0)$ & $4.6(0.1)$ & $3.5(0.1)$ & $16.0(0.4)$ & $94.1(0.2)$ & $8.2(0.0)$ & $8.2(0.1)^{\ddagger}$ & $7.1(0.1)$ & $73(6)$ & $95(14)$ & $2.5(0.1)$ & $0.9(0.0)$ \\
\hline & 12 & $81.1(0.7)$ & $5.6(0.2)$ & $3.9(0.1)$ & $14.3(0.4)$ & $95.0(0.2)$ & $8.6(0.5)$ & $8.1(0.1)$ & $8.7(0.1)$ & $57(5)$ & $76(11)$ & $2.5(0.1)$ & $0.9(0.0)$ \\
\hline \multirow[t]{5}{*}{ Sterile canteen waste } & 0 & $69.5(0.2)^{\ddagger}$ & $4.4(0.0)^{\ddagger}$ & $2.9^{\dagger}$ & $19.3^{\dagger}$ & $95.9(0.0)^{\ddagger}$ & n.a. & n.a & n.a & $125^{\dagger}$ & $143^{\dagger}$ & $2.4^{\dagger}$ & $0.8^{\dagger}$ \\
\hline & 3 & $68.2(0.5)$ & $3.9(0.1)$ & $3.1(0.2)$ & $17.6(1.4)$ & $95.9(0.4)$ & $8.6(0.0)$ & $8.6(0.1)$ & $6.4(0.1)$ & $78(12)$ & $101(10)$ & $1.5(0.2)$ & $0.6(0.1)$ \\
\hline & 6 & $69.5(0.2)$ & $3.8(0.0)$ & $3.0(0.1)$ & $18.2(0.7)$ & $95.4(0.1)$ & $8.5(0.1)$ & $8.5(0.1)$ & $6.9(0.2)$ & $62(5)$ & $84(20)$ & $1.4(0.2)$ & $0.6(0.1)$ \\
\hline & 9 & $72.0^{\dagger}$ & $3.9^{\dagger}$ & $3.0^{\dagger}$ & $18.0^{\dagger}$ & $95.3^{\dagger}$ & $8.3^{\dagger}$ & 8.0 & $7.2^{\dagger}$ & $53^{\dagger}$ & $66^{\dagger}$ & $2.0^{\dagger}$ & $0.8^{\dagger}$ \\
\hline & 12 & $73.6(1.2)^{\ddagger}$ & $4.2(0.0)$ & $3.1(0.1)$ & $17.9(0.8)^{\ddagger}$ & $95.8(0.1)^{\ddagger}$ & $9.3(0.1)^{\ddagger}$ & $8.2(0.1)^{\ddagger}$ & $9.0(0.1)^{\ddagger}$ & $63(14)^{\ddagger}$ & $89(30)^{\ddagger}$ & $2.4(0.1)^{\ddagger}$ & $0.9(0.0)^{\ddagger}$ \\
\hline \multirow[t]{5}{*}{ Household waste } & 0 & $76.7(0.1)^{\ddagger}$ & $4.8(0.0)^{\ddagger}$ & $3.1^{\dagger}$ & $16.7^{\dagger}$ & $94.3(0.1)^{\ddagger}$ & $9.2(0.1)$ & $9.0(0.3)^{\ddagger}$ & $5.4(0.2)$ & $122^{\dagger}$ & $147^{\dagger}$ & $2.6^{\dagger}$ & $0.9^{\dagger}$ \\
\hline & 3 & $79.4(0.2)^{\ddagger}$ & $3.9(0.0)^{\ddagger}$ & $3.3^{\dagger}$ & $15.8^{\dagger}$ & $93.7(0.0)^{\ddagger}$ & $8.6(0.1)^{\ddagger}$ & $8.7(0.1)^{\ddagger}$ & $6.6(0.1)^{\ddagger}$ & $122(52)^{\ddagger}$ & $142(61)^{\ddagger}$ & $2.0(0.6)^{\ddagger}$ & $0.7(0.2)^{\ddagger}$ \\
\hline & 6 & $83.0(0.5)$ & $3.9(0.0)$ & $3.2(0.1)$ & $16.5(0.4)$ & $92.1(0.4)$ & $8.0(0.1)$ & $7.9(0.1)$ & $6.3(0.2)$ & $99(7)$ & $122(13)$ & $2.3(0.1)$ & $0.8(0.0)$ \\
\hline & 9 & $88.2(0.4)$ & $4.5(0.1)$ & $3.2(0.1)$ & $15.7(0.5)$ & $88.8(0.4)$ & $7.6(0.1)$ & $7.6(0.1)$ & $5.0(0.1)$ & 67 (9) & $89(14)$ & $2.1(0.0)$ & $0.8(0.0)$ \\
\hline & 12 & $90.2(0.3)$ & $6.5(0.6)$ & $3.6(0.1)$ & $13.8(0.5)$ & $85.5(0.6)$ & $10.0(0.5)$ & $7.5(0.0)$ & $7.5(1.3)^{\ddagger}$ & $62(5)$ & $88(9)$ & $2.2(0.1)$ & $0.8(0.0)$ \\
\hline \multicolumn{14}{|l|}{ Without BSFL } \\
\hline Canteen waste & 12 & $72.2(0.3)$ & $4.8(0.3)$ & $3.8(0.0)^{\ddagger}$ & $14.8\left(0.2^{\ddagger}\right.$ & $95.2(0.1)^{\ddagger}$ & n.a & n.a & n.a & $106(4)^{\ddagger}$ & $122(10)^{\ddagger}$ & $2.7(0.0)^{\ddagger}$ & $0.9(0.0)^{\ddagger}$ \\
\hline Sterile canteen waste & 12 & $66.9(0.4)$ & $4.0(0.1)$ & $3.1(0.1)$ & $17.2(0.5)$ & $95.7(0.0)^{\ddagger}$ & n.a & n.a & n.a & $97(9)$ & $133(11)$ & $1.6(0.3)$ & $0.6(0.1)$ \\
\hline
\end{tabular}

See Supplementary Table 2 for the carbon, water activity, and temperature results. In parenthesis: standard deviation for samples where $n \geq 3$, differences between analyses where $n=2$. ${ }^{\dagger} n=1$, $\ddagger n=2$, n.a., not analyzed. C/N: carbon to nitrogen ratio. Richness: The number of ZOTUs determined with 16S rRNA gene sequencing based on DNA extracted from samples. Chao 1: the total number of ZOTUs estimated by infinite sampling. A higher number indicates a higher richness (Chao, 1984). Shannon Index: Measure richness and evenness. Increases with community richness and evenness (Shannon and Weaver, 1949; Lemos et al., 2011). Simpson's Index: Measures community evenness. Index increases as diversity decreases (Simpson, 1949; Lemos et al., 2011). 


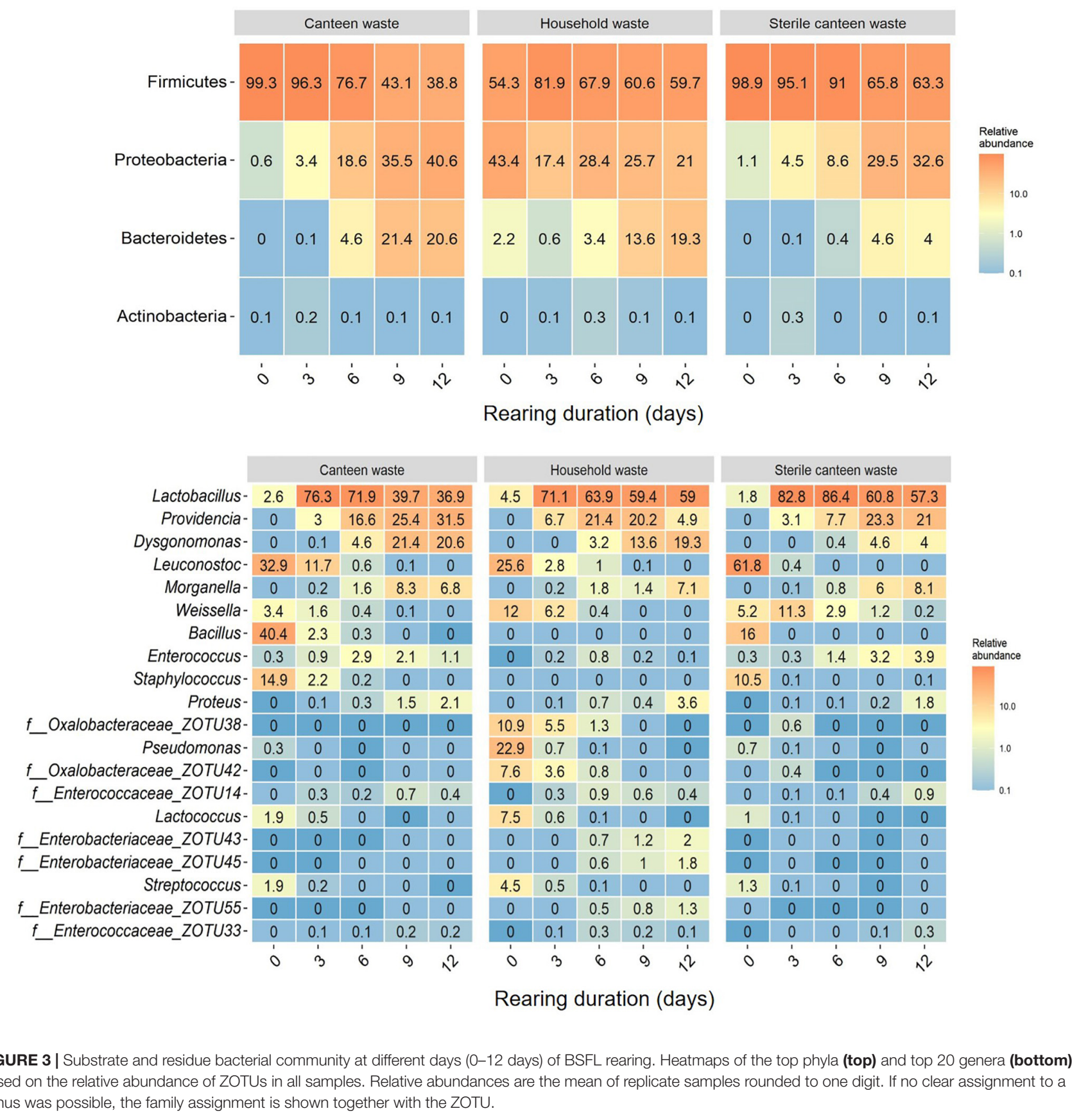

based on the relative abundance of ZOTUs in all samples. Relative abundances are the mean of replicate samples rounded to one digit. If no clear assignment to a genus was possible, the family assignment is shown together with the ZOTU.

dramatically changed the bacterial richness (Table 2) and community (Figures 3, 4). Community richness decreased on both wastes throughout rearing, and the bacterial community between the two substrates became more similar. Replicate samples clustered well based on UniFrac distances according to rearing day and substrate. After 3 days of rearing, the bacterial communities were more similar to each other than the initial wastes (Figure 4A). Changes in the bacterial community were the largest within the first 6 days. The similarity between bacterial communities decreased again following 9 days. In both residues, most bacteria belonged to the genus Lactobacillus. Throughout the rearing period, the phyla Proteobacteria and Bacteroidetes, and the genera Providencia, Dysgonomonas, Morganella, and Proteus became more abundant than in the substrate.

\section{Sterile Canteen Waste}

Despite complete microbial inactivation by irradiation, the sterile canteen waste substrate had a similar bacterial community as the non-sterile canteen waste (Table 2 and Figures 3, 4B). Sterile canteen waste and canteen waste shared ZOTUs that accounted for $99.5 \%$ of the relative abundance (see Venn diagram in Supplementary Figure 6). Bacterial dynamics were also similar 


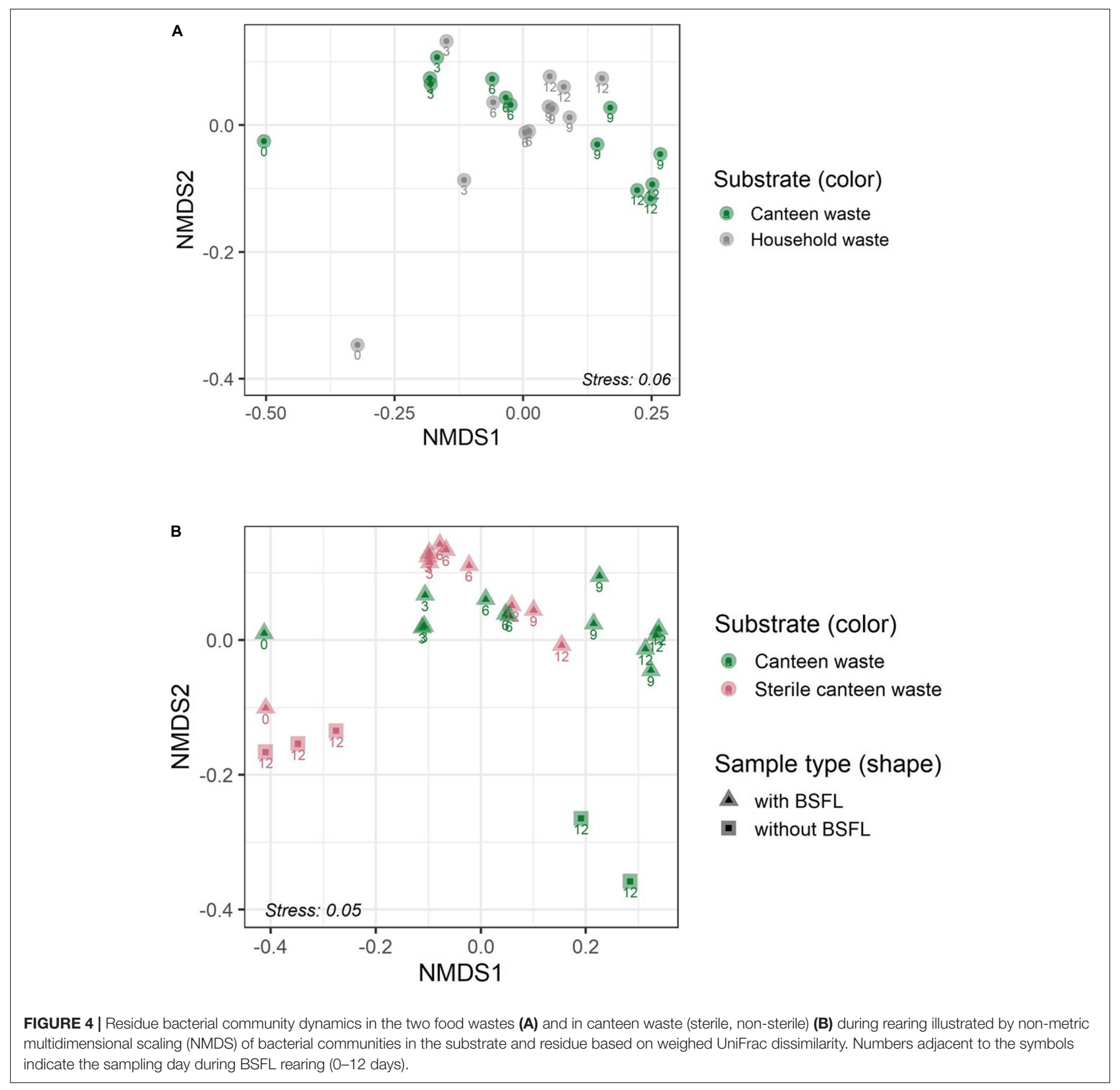

between sterile and non-sterile canteen waste (Figure 4B). The addition of BSFL to the sterile canteen waste led to a repopulation of the substrate to microbial counts similar to those determined in the non-sterile canteen waste (Table 2). Lactobacillus was also highly abundant in the sterile canteen waste residues, decreased in abundance during rearing, and Providencia, Dysgonomonas, Morganella, and Proteus became more abundant, but to a smaller extent compared to non-sterile canteen waste.

\section{Substrates Without Larvae}

The bacterial community of sterile canteen waste was similar to the initial bacterial community of the canteen waste substrates, after 12 days of storage (Figure 4B). However, for both sterile and non-sterile canteen waste, it differed noticeably from the bacterial communities in the rearing residues (Figure 5). The substrates stored without larvae had a higher bacterial richness (Table 2) and Leuconostoc, Stenotrophomonas, Hafnia-Obesumbacterium, Lactococcus, and Enterobacteriaceae were highly abundant but absent in the rearing residues (Figure 5). Genera that became more abundant in the rearing residues (see section "Substrates Without Larvae," i.e., Providencia, Dysgonomonas, Morganella, and Proteus) were absent from the substrates stored without larvae. 
TABLE 3 | Literature summary of bacterial communities in BSFL rearing residues.

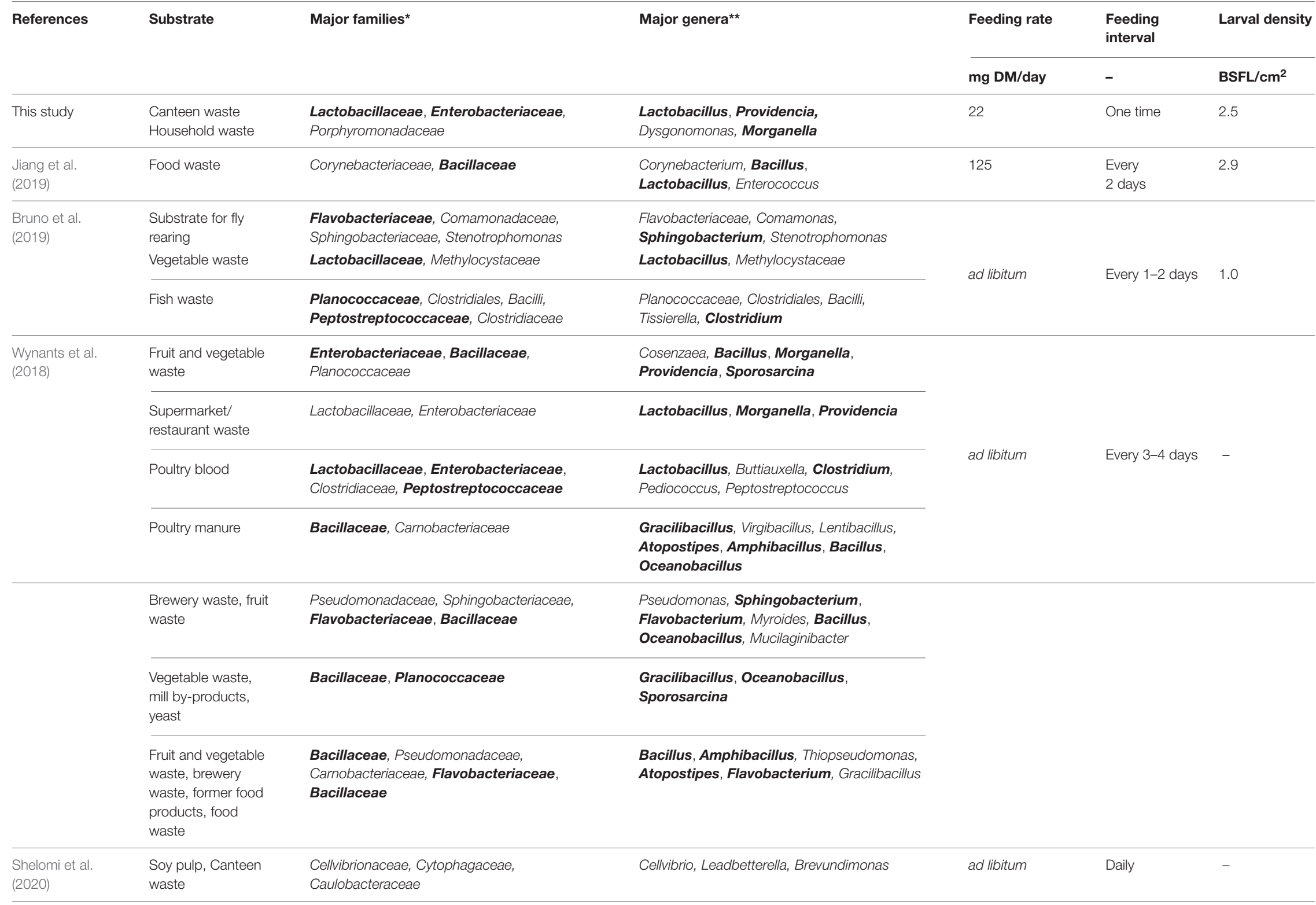

Families and genera identified in at least two studies are highlighted in bold. The bacterial community was identified in all studies by 165 rRNA gene sequencing. * relative abundance $>10 \%$, in order of descending relative abundance. ** relative abundance $>5 \%$, in order of descending relative abundance; whenever the genera could not be identified, the lowest available taxonomic rank (i.e., family or class) is reported. 


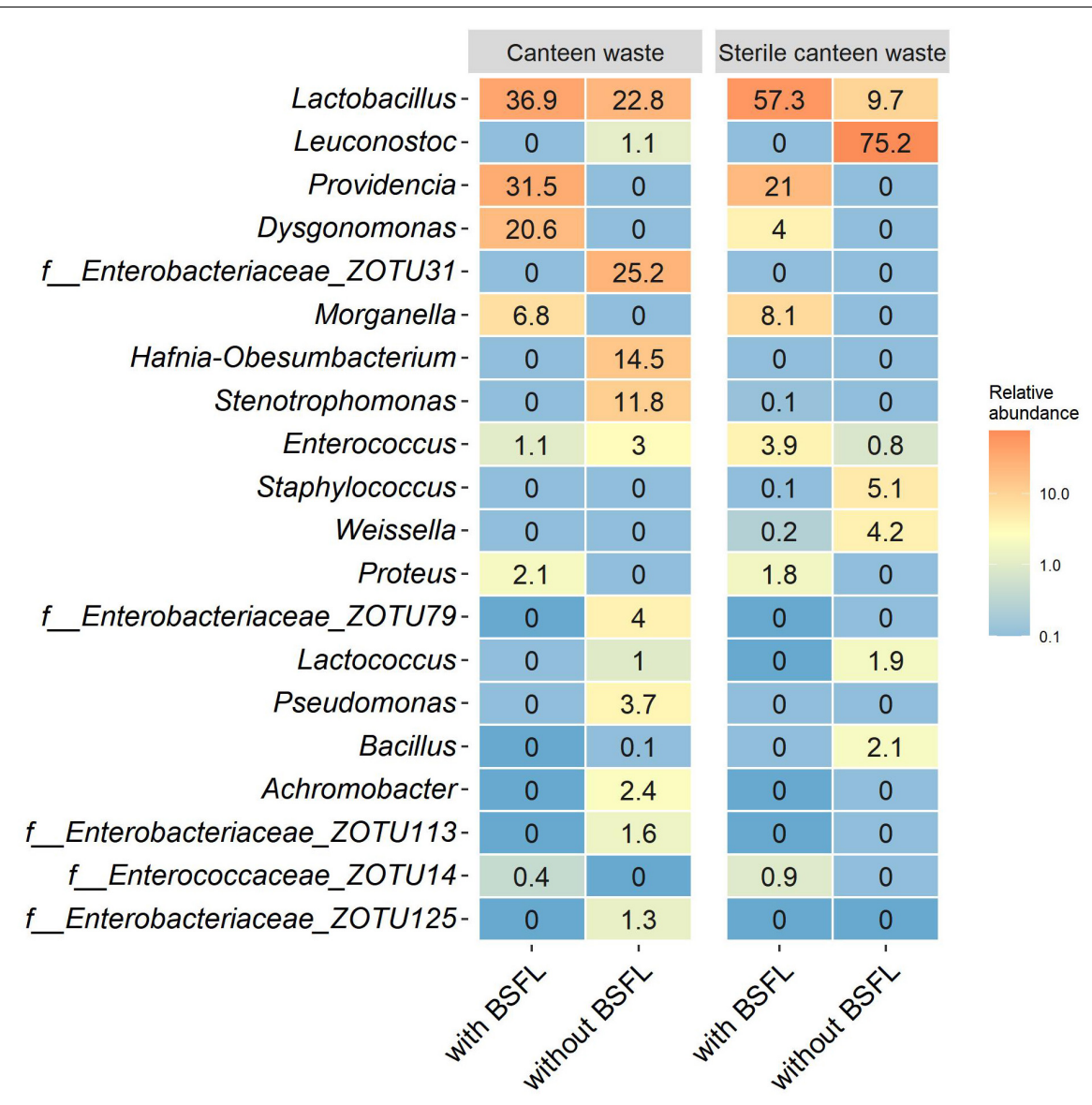

FIGURE 5 | Bacterial community in canteen waste (sterile, non-sterile) with and without larvae following 12 days of rearing or storage. Heatmaps of the top 20 genera based on the relative abundance of ZOTUs in all samples. Relative abundances are the mean of replicate samples rounded to one digit. If no clear assignment to a genus was possible, the family assignment is shown together with the ZOTU.

\section{Correlation Among Bacterial Community, Rearing Performance, and Residue Composition}

Bacterial community dynamics correlated with rearing performance and physicochemical properties and composition of the residue (Figure 6). Of all parameters, larval weight, and residue $\mathrm{pH}$, carbon, nitrogen, and water activity had the lowest co-linearity and were used in distance-based redundancy analysis (dbRDA). The global dbRDA model and the first two axes were statistically significant and explained $83.5 \%$ of the variability in the bacterial community.

\section{DISCUSSION}

\section{Substrate Microbiota Contributes to Rearing Performance}

We compared results for substrate and residue bacterial communities and BSFL rearing performance indicators between sterile and non-sterile canteen waste. We hypothesized that inactivation of the initial bacterial community in the rearing substrate will decrease rearing performance and reveal important members of the microbiota influencing improved rearing performance.

Our hypothesis was confirmed as results show that inactivation of microbes in the substrate reduced rearing performance (Figures 1, 2), suggesting that the initial substrate microbial community contributes to substrate decomposition and/or larval growth. The initial canteen waste microbial community was dominated by LAB (Figure 3), which is typical for fermented foods (Wu et al., 2018) and grain-based substrates (Wynants et al., 2019) with high contents of digestible carbohydrates (i.e., starch) (Table 1) and low pH (Table 2). LAB that have been shown to promote the growth of Drosophila melanogaster (Shin et al., 2016; Storelli et al., 2018), are routinely used as feed additives to promote the growth of farmed animals (e.g., poultry, pigs, and cattle) (Vieco-Saiz et al., 2019), and the addition of LAB (e.g., Lactobacillus buchneri) to the substrate has been shown to increase BSFL rearing performance (Somroo et al., 2019; Mazza et al., 2020). The mechanisms by which LAB promote growth are debated and still part of ongoing research, but suggestions include an increase of the metabolic capacity by fermentation of substrate carbohydrates into short chain 


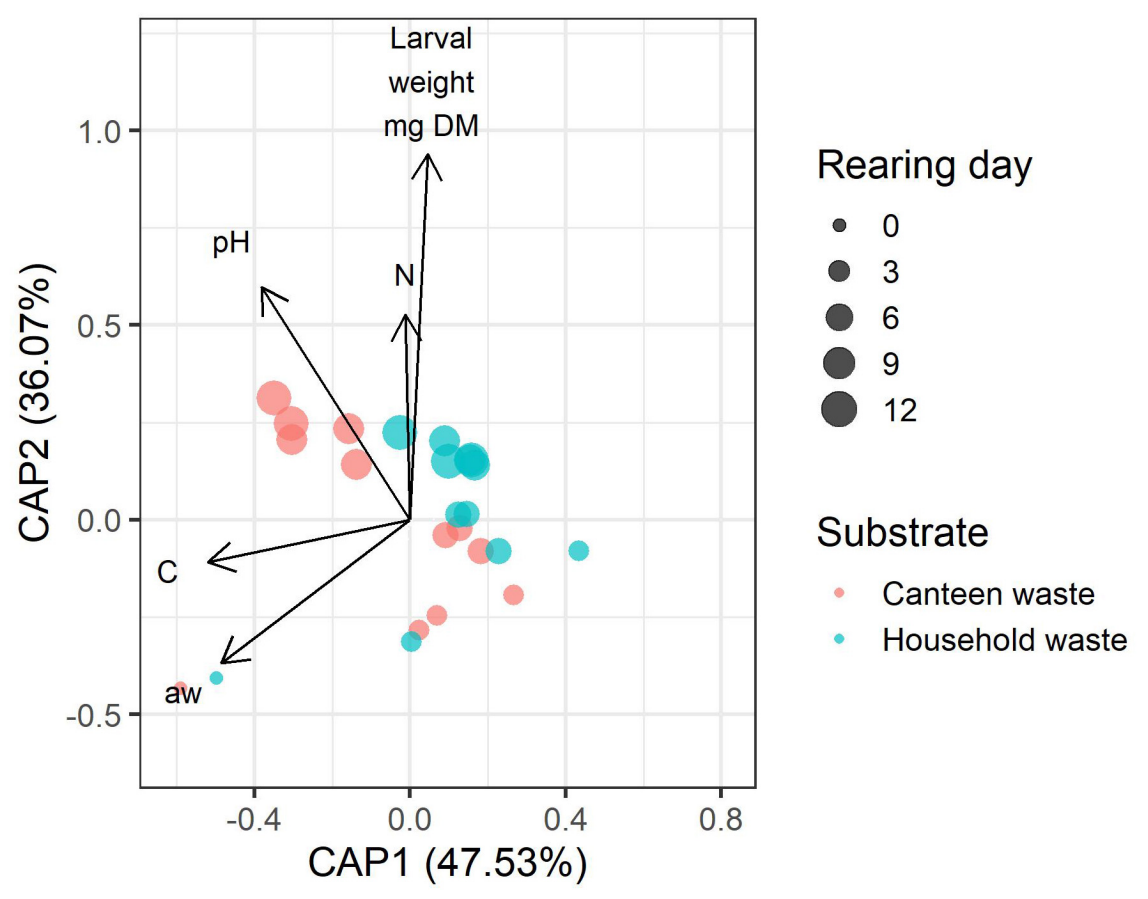

FIGURE 6 | Distance-based redundancy analysis (dbRDA) biplot of canteen waste and household waste samples showing the correlation between the physicochemical properties and composition of the residue $\left(\mathrm{pH}, \mathrm{N}, \mathrm{C}, \mathrm{a}_{\mathrm{w}}\right)$, larval weight, and the bacterial community. The length of the vectors indicates the relative importance of the parameter. The vector angle between variables indicates a correlation. Variables with smaller angles between vectors have a closer positive correlation. Perpendicular vectors indicate that there is no correlation. Vectors pointing in opposite directions indicate a negative correlation. Shorter distance between points indicates similarity between bacterial communities.

fatty acids (as indicated by the low $\mathrm{pH}$ in the residue, Table 2), growth signaling, immunity, and protection and maintenance of stable gut microbiomes (Holzapfel et al., 2001). Interestingly, bacteria and fungi in the digestive tract or on the surface of larvae repopulated the high-energy electron beam treated canteen waste during rearing (Table 2) but rearing performance indicators remained nevertheless lower given the loss of the initial microbial community (Figures 1, 2).

Intact DNA after high-energy beam treatment interfered with further interpretation of bacterial dynamics in the sterile canteen residue. Despite lethal irradiation doses (Gold et al., 2020b), similar bacterial community between sterile and nonsterile canteen waste (Figure 3) after 12 days indicates that some bacterial DNA remained intact and was considered in the bacterial community based on DNA sequencing. As the bacterial communities identified in the sterile canteen waste residue may also include members without any major metabolic functions, these results should be interpreted with caution and are not further discussed. This finding agrees with recent research on the effect of irradiation on bacteria. Hieke and Pillai (2018) reported that Escherichia coli maintain their cell integrity post-irradiation, which protects DNA from denaturation. Since larvae and the associated microbiota digest bacteria (Gold et al., 2018), it is possible that the determined bacterial community becomes more representative of the viable bacterial community with increasing rearing duration.

\section{Rearing Performance Between the Two Food Wastes}

While it has been recognized that both the rearing substrate nutrient composition and the microbial community (De Smet et al., 2018) composition influence rearing efficiency and reliability, previous studies typically emphasized only one aspect (Bruno et al., 2019; Klammsteiner et al., 2020) or considered both aspects but in isolation (Wynants et al., 2019; Gold et al., 2020a). We determined both substrate nutrient contents and bacterial communities and this over the rearing duration. We purposely used two rearing substrates with similar nutrient contents. Thereby we expected that the differences in rearing performance could be more easily attributed to the different substrate bacterial communities and could reveal members associated with rearing performance rather than showing the effect of nutritional differences.

Rearing performance was high with both food wastes (Figures 1, 2). We expected this based on the high nutrient contents (Table 1). Previous studies have reported lower bioconversion rates for food waste of 13.9-22.7\% DM (Nyakeri et al., 2017; Lalander et al., 2019; Gold et al., 2020a) as compared to $23.5-28.0 \% \mathrm{DM}$ in this study. Waste streams with low nutrient contents, such as digested waste water sludge, or cow and poultry manure, typically have even much lower bioconversion rates of 2.2-3.8\% DM (Lalander et al., 2019; Gold et al., 2020a). Since the bioconversion rate is a key 
indicator determining the economics of insect rearing and the environmental sustainability of insect-derived products (Smetana et al., 2019), the results show that food waste could be an especially viable substrate for BSFL rearing.

Rearing performance was similar between the two rearing substrates with regard to conversion efficiency (Figure 1). However, larval biomass production (Figure 1) and waste reduction (Figure 2A) were higher for household than for canteen waste substrates. As demonstrated by the reduction in rearing performance due to the loss of the initial microbial community, differences in the initial substrate bacterial community could have contributed to the differences in this rearing performance. Notably, between the two substrates, there was a considerably higher waste reduction within the first 3 days of rearing (Figure 2A). However, as the two substrates shared most taxa, no conclusions can be drawn on bacteria that may explain the differences in rearing performance between substrates. It appears to be more likely that the disparity in rearing performance between substrates is due to different content and digestibility of nutrients. For example, non-fiber carbohydrates in household waste are likely more digestible for BSFL, considering that they were mostly comprised of glucose and fructose (Table 1). Pimentel et al. (2018) demonstrated that Musca domestica larvae can directly absorb glucose in the anterior and posterior midgut. Starch, however, requires catalysis before absorption and comprises all non-fiber carbohydrates in the canteen waste (Table 1) therefore being less directly digestible. In addition, household waste digestibility may have been increased by the onset of microbial substrate decomposition during storage (i.e., in the order of hours to days) at the household level (Albuquerque and Zurek, 2014). In contrast, canteen waste was collected on the same day of waste generation and stored at $4^{\circ} \mathrm{C}$.

In summary, these findings demonstrate the challenge of unambiguously identifying the causes for differences in rearing performance despite comprehensive analysis of nutrient contents and bacterial communities. Differences in rearing performance could be due to differences in the low-abundance taxon or due to differences on the species level for the same genus. In addition, although Bruno et al. (2019) and Klammsteiner et al. (2020) concluded that bacterial gut communities are rather similar between substrates with broadly similar nutrient contents (Table 1), differences in bacterial community structure and function among substrates, as demonstrated by Zhan et al. (2020), may also have contributed to rearing performance differences.

\section{Common Fly Associated Bacteria Dominate the Rearing Residue}

Microbial dynamics in the rearing residues of BSFL are still poorly understood. We studied bacterial community dynamics to identify taxa that were more abundant during BSFL rearing and that were absent in the controls (i.e., substrates stored under the same environmental conditions but without larvae). As suggested by previous researchers (Zhao et al., 2017; Ao et al., 2020), we hypothesized that bacteria enriched in the rearing residue contribute to substrate decomposition. This could imply that pure-culture bacteria and/or defined bacterial mixtures comprised of these bacteria from the residue could potentially increase large-scale BSFL rearing.

Previous studies have reported inconsistent results on the significance of altered substrate bacterial community during BSFL rearing (Bruno et al., 2019; Jiang et al., 2019; Cifuentes et al., 2020). Our study confirmed that BSFL rearing dramatically changes the substrate bacterial community and physicochemical properties and composition. For example, consistent with previous research, the $\mathrm{pH}$ increased in the residue during BSFL rearing (Table 2; Erickson et al., 2004; Lalander et al., 2014; Ma et al., 2018; Jiang et al., 2019; Wynants et al., 2019; Klammsteiner et al., 2020). Characteristic for food waste decomposition, the residue $\mathrm{pH}$ initially decreased due to the hydrolysis of proteins (Wu et al., 2018). Following 6 days of rearing, the $\mathrm{pH}$ increased beyond the initially value in the substrate, presumably due to the excretion of nitrogenous compounds by BSFL (e.g., uric acid) (Klammsteiner et al., 2020). Similar to the results of Jiang et al. (2019), ordination plots (Figure 4) revealed an obvious succession of the bacterial community throughout BSFL rearing. Consistent with previous research by Jiang et al. (2019) and Wynants et al. (2018), this study observed a reduction in bacterial richness (Table 2) in the residue in comparison to the substrate over the rearing duration. In contrast to Wynants et al. (2018) and Jiang et al. (2019), Bruno et al. (2019) did not observe significant differences in the bacterial community between substrates and residues, and Cifuentes et al. (2020) observed an increase in bacterial richness. Different abiotic (e.g., temperature, substrate nutrient content, and $\mathrm{pH}$ ) and biotic (e.g., initial substrate bacterial communities) factors known to influence microbial ecology and the presence and stability of antimicrobial proteins by BSFL (De Smet et al., 2018; Vogel et al., 2018) may provide some explanation for discrepancies in findings among studies. Wynants et al. (2018) studied BSFL rearing with a variety of mostly grain-based substrates in several laboratory and industry-scale settings, Jiang et al. (2019) with food waste in an industry-scale setting, and Bruno et al. (2019) with a standard substrate for fly rearing, vegetables and fish waste in a laboratory setting (Table 3). Considering that substrate digestion by BSFL (Cai et al., 2018; Bruno et al., 2019) and other fly larvae (e.g., Lucilia sericata, Diptera: Calliphoridae) (Mumcuoglu et al., 2001; Lerch et al., 2003) decreases bacterial richness along the digestive tract (Gold et al., 2018; Vogel et al., 2018), different feeding rates, intervals, and larval densities among studies could be especially relevant (Table 3 ). One could expect that the substrate and residue bacterial community is altered to a greater extent by BSFL when less feed is provided per larvae (i.e., lower feeding rate and/or higher larval density). Our study and that of Jiang et al. (2019) had a 2-3-fold higher larval density and feed was provided less frequently when compared to Bruno et al. (2019), thus allowing more time for larval digestion (Table 3). Cifuentes et al. (2020) provided an insufficient rearing protocol to allow comparison with the other studies. A further study focusing more on microbial dynamics in BSFL under different rearing parameters is therefore recommended. However, considering the results of 
this and previous studies, and that large-scale rearing facilities may have higher larval densities [e.g., 4 larvae per $\mathrm{cm}^{2}$ by Dortmans et al. (2017)], a lower number of bacterial species can be expected in well-digested residues in comparison to the initial substrates.

Genera in the residues at the time of larval harvest are ubiquitous in the environment (e.g., soil, water, digestive tracts of humans, and farmed animals) and have been previously identified in different life stages of the BSF (Table 3; Bruno et al., 2019; Cifuentes et al., 2020; Klammsteiner et al., 2020; Raimondi et al., 2020; Zhan et al., 2020), Musca domestica (Zurek et al., 2000; Su et al., 2010; Gupta et al., 2012), and Lucilia sericata (Singh et al., 2014). Bacteria commonly associated with BSFL residues (Table 3 ) are from the Lactobacillaceae, Bacillaceae, Enterobacteriaceae, Planococcaceae, and Flavobacteriaceae families. One possible explanation for the recurrence of these taxa in fly larvae residues is through the transfer of intestinal commensal bacteria with larval secretions and excretions into the residue (Zhao et al., 2017; Storelli et al., 2018). The results of this study support this hypothesis. Recurring taxa in the residues belong to the phyla Firmicutes, Proteobacteria, and Bacteroidetes, which are the main intestinal bacteria in fly larvae (Zurek et al., 2000; Jeon et al., 2011; Boccazzi et al., 2017; Scully et al., 2017; Cifuentes et al., 2020; Liu et al., 2020). Providencia spp., Dysgonomonas spp., Morganella spp., and Proteus spp. present in the BSFL residues, and absent in controls without larvae, are highly abundant in the BSFL guts (Ao et al., 2020; Cifuentes et al., 2020; Klammsteiner et al., 2020; Raimondi et al., 2020). Identification of Dysgonomonas, Providencia, Morganella, and Proteus in the posterior midgut of BSFL suggest that members of these genera may survive gut passage (Bruno et al., 2019). The one-time feeding regime, low feeding rate, and high larval density in our experiments could have contributed to the more pronounced appearance of these genera than in previous studies (Bruno et al., 2019; Wynants et al., 2019), as the residue presumably passed the digestive tract more often than that at higher feeding rates and frequency and lower larval densities. However, it is important to bear in mind that these genera are typically present at low abundance $(<0.01 \%$ in this study) in BSFL substrates (see Figure 3; Bruno et al., 2019; Shelomi et al., 2020). Consequently, the proliferation of these genera during BSFL rearing could also have been in part due to the observed changes in the residue physicochemical properties and composition, and not only the secretions/excretions of BSFL. For example, members of the genera Proteus, Providencia, and Morganella are involved in urea hydrolysis and thus may benefit from the nitrogenous compounds excreted by BSFL (Manos and Belas, 2006; Klammsteiner et al., 2020).

Dysgonomonas, Providencia, Proteus, and Morganella have important functions in the life cycle of fly species. Despite their prominence in the digestive tracts and residues, the ways in which they influence larvae and substrate decomposition are still poorly understood. Studies focusing on the role of these bacteria in BSFL rearing do not exist. Morganella spp. and Providencia spp. are typically transferred between generations in several fly species ( $\mathrm{Su}$ et al., 2010), and Proteus spp. have been isolated from the egg surface of the BSF (Mazza et al., 2020) and the digestive tract of Musca domestica (Su et al., 2010; Gupta et al., 2012). One function of these bacteria appears to be stimulation of the fly ovipositor by the release of volatile compounds. Different species of these genera, such as Proteus mirabilis, have been shown to control fly oviposition in Lucilia sericata (Ma et al., 2012; Tomberlin et al., 2012; Uriel et al., 2020) and Cochliomyia hominivorax (Diptera: Calliphoridae) (DeVaney et al., 1973; Eddy et al., 1975). In addition, $P$. mirabilis may repel bacteria that are detrimental to larval development. P. mirabilis is associated with Lucilia sericata and exerts bactericidal effects (Erdmann and Khalil, 1986), but the antimicrobial excretion/secretion from Lucilia sericata is not active against $P$. mirabilis, suggesting a symbiotic host-microbe relationship (Barnes et al., 2010). In addition, bacteria may support the decomposition of substrate constituents (Zhao et al., 2017). Bruno et al. (2019) identified Dysgonomonas and Ao et al. (2020) Providencia as major genera in the BSFL digestive tracts and proposed that their members could be involved in the digestion of hemicellulose and proteins and lipids, respectively. Similarly, Dysgonomonas and Providencia could contribute to nutrient decomposition in the residue. However, it should be noted that there is considerable uncertainty with these claims as they are based on findings for phylogenetically different well-studied insects (e.g., honeybees and termites), correlations between bacterial communities and environmental parameters (e.g., substrate nutrients), or functional predictions based on DNA sequencing, which may not provide direct evidence for bacterial community functional capacities.

We demonstrated that there is considerable overlap between bacterial communities in BSFL residues and digestive tracts. We hypothesize that some members of these genera may influence substrate decomposition and larval development, and therefore have the potential to increase the performance of large-scale BSFL rearing. A natural progression of this work is to isolate members of these genera from residues or larval digestive tracts, and assess their potential to increase rearing performance by adding them to the rearing substrates in vivo (Yu et al., 2011; Xiao et al., 2018; Rehman et al., 2019; Somroo et al., 2019; Mazza et al., 2020) and in vitro (Gold et al., 2020c). Further research is needed to better understand the variable effectiveness among bacterial species (Mazza et al., 2020), and among strains of the same species (Yu et al., 2011), in influencing rearing performance under variable biotic and abiotic conditions typical in practice. These studies should use or imitate large-scale rearing conditions (e.g., larval densities) to ensure maximum transfer of results into practice. Even though we used realistic rearing conditions (i.e., feeding rates and larval densities), residue temperatures $\left(27-30^{\circ} \mathrm{C}\right)$ influencing bacterial communities in BSFL (Raimondi et al., 2020) were below those found in large-scale rearing (e.g., $33-45^{\circ} \mathrm{C}$ ) (Bloukounon-Goubalan et al., 2019) due to the benchscale nature of our study.

\section{Implications for Product Safety}

Despite not being the main focus of this research, our results present relevant findings regarding BSFL rearing product 
safety. BSFL substrates may have pathogenic microbes (Erickson et al., 2004; Lalander et al., 2013) and since BSFL live within their rearing substrate and pass it through their digestive tract, pathogenic microbes inside or on the harvested larvae are a hazard for product safety. Such pathogenic microbes in the harvested larval biomass can be eliminated by thermal or non-thermal inactivation technologies. An alternative approach could be the inactivation of pathogenic microbes in the substrate before BSFL rearing, for instance by irradiation. Our results suggest that such an approach may greatly decrease rearing performance. Future research should be undertaken to mimic more realistically rearing facility substrate inactivation technologies (e.g., pasteurization) and conditions (e.g., time, temperature). Some technologies may only lead to partial microbial inactivation and at the same time reduce particle size and increase nutrient digestibility, impacting positively on rearing performance. However, considering that fly larvae may live in close association with pathogens such as Providencia rettgeri, $P$. mirabilis, and Morganella morganii, post-harvest treatment of the residue (e.g., composting) and larval biomass (e.g., heat treatment such as pasteurization) may still be the most efficient and reliable approach.

\section{CONCLUSION}

Sustainable mass rearing of BSFL for feed and food applications requires efficient and reliable process performance. Complementing previous work on the larval microbiota, this study set out to identify bacterial taxa in two food waste rearing substrates and residues that are potentially associated with rearing performance. As expected, considering their high nutrient content, rearing performance was high with canteen and household food waste substrates, underlining their potential for efficient insect production. A loss of the initial food waste microbiota, dominated by lactic acid bacteria, decreased rearing performance, indicating that initial substrate microbiota influence the complex bioconversion process. Furthermore, the rearing performance could also be influenced by bacteria in the rearing residue. Rearing duration decreased the bacterial richness and changed the physicochemical properties and composition of the residue, and typical members of the larval intestinal microbiota (that is, Providencia, Dysgonomonas, Morganella) became more abundant, suggesting their transfer into the residue through excretions. The present study provides a scientific basis for future studies that should

\section{REFERENCES}

Albuquerque, T. A., and Zurek, L. (2014). Temporal changes in the bacterial community of animal feces and their correlation with stable fly oviposition, larval development, and adult fitness. Front. Microbiol. 5:590. doi: 10.3389/ fmicb.2014.00590

Andersen, K. S., Kirkegaard, R. H., and Albertsen, M. (2018). ampvis2: an R package to analyse and visualise $16 \mathrm{~S}$ rRNA amplicon data. bioRxiv [Preprint] doi: $10.1101 / 299537$ isolate these bacteria and assess their true role in influencing rearing performance.

\section{DATA AVAILABILITY STATEMENT}

All original data presented in the study is publicly available. This sequencing data can be found at: https://www.ncbi.nlm.nih.gov/ PRJNA646490. All other data and analyses can be found at: https: //github.com/MoritzGold/BSFL_residue_microbiota.

\section{AUTHOR CONTRIBUTIONS}

MG: conceptualization, methodology, investigation, formal analysis, visualization, writing - original draft, and funding acquisition. FA: conceptualization, methodology, investigation, formal analysis, visualization, and writing - review and editing. CZ: conceptualization, supervision, project administration, funding acquisition, and review and editing. JZ: writing review and editing. AM: conceptualization, supervision, project administration, writing - review and editing, and funding acquisition. All authors contributed to the article and approved the submitted version.

\section{FUNDING}

This research was funded by the Sawiris Foundation for Social Development [Engineering for Development (E4D) Scholarship Program], Eawag, the ETH Zürich Foundation, ETH Global, and Bühler AG.

\section{ACKNOWLEDGMENTS}

Metagenomic analyses were completed at the Genetic Diversity Centre (GDC) at ETH Zürich, Switzerland. The authors are grateful to Aria Maya Minder Pfyl, Silvia Kobel, and Jean-Claude Walser at the GDC for the support in data generation and analysis.

\section{SUPPLEMENTARY MATERIAL}

The Supplementary Material for this article can be found online at: https://www.frontiersin.org/articles/10.3389/fmicb. 2020.582867/full\#supplementary-material

Ao, Y., Yang, C., Wang, S., Hu, Q., Yi, L., Zhang, J., et al. (2020). Characteristics and nutrient function of intestinal bacterial communities in black soldier fly (Hermetia illucens L.) larvae in livestock manure conversion. Microb. Biotechnol. doi: 10.1111/1751-7915. 13595 [Epub ahead of print].

Barnes, K. M., Dixon, R. A., and Gennard, D. E. (2010). The antibacterial potency of the medicinal maggot, Lucilia sericata (Meigen): variation in laboratory evaluation. J. Microbiol. Methods 82, 234-237. doi: 10.1016/j.mimet.2010.06. 005 
Barragán-Fonseca, K., Pineda-Mejia, J., Dicke, M., and Van Loon, J. J. A. (2018). Performance of the black soldier fly (Diptera: Stratiomyidae) on vegetable residue-based diets formulated based on protein and carbohydrate contents. J. Econ. Entomol. 111, 2676-2683.

Barragán-Fonseca, K. B., Dicke, M., and van Loon, J. J. A. (2017). Nutritional value of the black soldier fly (Hermetia illucens L.) and its suitability as animal feed a review. J. Insects Food Feed 3, 105-120. doi: 10.3920/jiff2016.0055

Berggren, Å., Jansson, A., and Low, M. (2019). Approaching ecological sustainability in the emerging insects-as-food industry. Trends Ecol. Evol. 34, 132-138. doi: 10.1016/j.tree.2018.11.005

Bernard, E., Villazana, J., Alyokhin, A., and Rose, J. (2020). Colonisation of finfish substrate inhabited by black soldier fly larvae by blow flies, bacteria, and fungi. J. Insects Food Feed 6, 291-304. doi: 10.3920/jiff2019.0044

Bloukounon-Goubalan, A. Y., Saïdou, C. A. A. M., Chrysostome, M., Kenis, G. L., and Amadji, A. M. (2019). Physical and chemical properties of the agro-processing by-products decomposed by larvae of Musca domestica and Hermetia illucens. Waste Biomass Valorization 11, 2735-2743. doi: 10.1007/ s12649-019-00587-z

Boccazzi, I. V., Ottoboni, M., Martin, E., Comandatore, F., Vallone, L., Spranghers, T., et al. (2017). A survey of the mycobiota associated with larvae of the black soldier fly (Hermetia illucens) reared for feed production. PLoS One 12:e0182533. doi: 10.1371/journal.pone.0182533

Bosch, G., Zhang, S., Oonincx, D. G., and Hendriks, W. H. (2014). Protein quality of insects as potential ingredients for dog and cat foods. J. Nutr. Sci. 3:e29. doi: $10.1017 /$ jns.2014.23

Broderick, N. A., and Lemaitre, B. (2012). Gut-associated microbes of Drosophila melanogaster. Gut Microbes 3, 307-321. doi: 10.4161/gmic.19896

Bruno, D., Bonelli, M., De Filippis, F., Di Lelio, I., Tettamanti, G., Casartelli, M., et al. (2019). The intestinal microbiota of Hermetia illucens larvae is affected by diet and shows a diverse composition in the different midgut regions. Appl. Environ. Microbiol. 85:e01864-18.

Cai, M., Ma, S., Hu, R., Tomberlin, J. K., Thomashow, L. S., Zheng, L., et al. (2018). Rapidly mitigating antibiotic resistant risks in chicken manure by Hermetia illucens bioconversion with intestinal microflora. Environ. Microbiol. 20, 4051-4062. doi: 10.1111/1462-2920.14450

Cappellozza, S., Leonardi, M. G., Savoldelli, S., Carminati, D., Rizzolo, A., Cortellino, G., et al. (2019). A first attempt to produce proteins from insects by means of a circular economy. Animals 9:258.

Chao, A. (1984). Nonparametric estimation of the number of classes in a population. Scand. J. Stat. 11, 265-270. doi: 10.2307/4615964

Chen, C., Chaudhary, A., and Mathys, A. (2020). Nutritional and environmental losses embedded in global food waste. Resour. Conserv. Recycl. 160:104912. doi: 10.1016/j.resconrec.2020.104912

Cifuentes, Y., Glaeser, S. P., Mvie, J., Bartz, J. O., Müller, A., Gutzeit, H. O., et al. (2020). The gut and feed residue microbiota changing during the rearing of Hermetia illucens larvae. Antonie Van Leeuwenhoek Int. J. Gen. Mol. Microbiol. 113, 1323-1344. doi: 10.1007/s10482-02001443-0

De Smet, J., Wynants, E., Cos, P., and Van Campenhout, L. (2018). Microbial community dynamics during rearing of black soldier fly larvae (Hermetia illucens) and its impact on exploitation potential. Appl. Environ. Microbiol. 84:e2722-17.

DeVaney, J. A., Eddy, G. W., Ellis, E. M., and Harrington, R. (1973). Attractancy of inoculated and incubated bovine blood fractions to screwworm flies (Diptera: Calliphoridae): role of bacteria. J. Med. Entomol. 10, 591-595. doi: 10.1093/ jmedent/10.6.591

Dortmans, B., Diener, S., Verstappen, B. M., and Zurbrügg, C. (2017). Black Soldier Fly Biowaste Processing: A Step-by-Step Guide. Dübendorf: Swiss Federal Institute of Aquatic Science and Technology.

Dou, Z., Toth, J. D., and Westendorf, M. L. (2018). Food waste for livestock feeding: feasibility, safety, and sustainability implications. Glob. Food Sec. 17, 154-161. doi: 10.1016/j.gfs.2017.12.003

Douglas, A. E. (2009). The microbial dimension in insect nutritional ecology. Funct. Ecol. 23, 38-47. doi: 10.1111/j.1365-2435.2008.01442.x

Eddy, G. W., DeVaney, J. A., and Handke, B. D. (1975). Response of the adult screwworm (Diptera: Calliphoridae) to bacteria inoculated and incubated bovine blood in olfactometer and oviposition tests. J. Med. Entomol. 12, 379381. doi: 10.1093/jmedent/12.3.379
Edgar, R. C. (2016a). SINTAX: a simple non-Bayesian taxonomy classifier for 16S and ITS sequences. bioRxiv [Preptrint] doi: 10.1101/074161

Edgar, R. C. (2016b). UNOISE2: improved error-correction for Illumina $16 \mathrm{~S}$ and ITS amplicon sequencing. bioRxiv [Preprint] doi: 10.1101/081257

Engel, P., and Moran, N. A. (2013). The gut microbiota of insects - diversity in structure and function. FEMS Microbiol. Rev. 37, 699-735. doi: 10.1111/15746976.12025

Erdmann, G. R., and Khalil, S. K. W. (1986). Isolation and identification of two antibacterial agents produced by a strain of Proteus mirabilis isolated from larvae of the screwworm (Cochliomyia hominivorax) (Diptera: Calliphoridae). J. Med. Entomol. 23, 208-211. doi: 10.1093/jmedent/23.2.208

Erickson, M. C., Islam, M., Sheppard, D. C., Liao, J., and Doyle, M. P. (2004). Reduction of Escherichia coli O157:H7 and Salmonella enterica serovar enteritidis in chicken manure by larvae of the black soldier fly. J. Food Prot. 67, 685-690. doi: 10.4315/0362-028x-67.4.685

Ermolaev, E., Lalander, C., and Vinnerås, B. (2019). Greenhouse gas emissions from small-scale fly larvae composting with Hermetia illucens. Waste Manag. 96, 65-74. doi: 10.1016/j.wasman.2019.07.011

European Commission (2009). Commission Regulation (EC) No 152/2009. Brussels: Official Journal of the European Union.

Gold, M., Cassar, C. M., Zurbrügg, C., Kreuzer, M., Boulos, S., Diener, S., et al. (2020a). Biowaste treatment with black soldier fly larvae: increasing performance through the formulation of biowastes based on protein and carbohydrates. Waste Manag. 102, 319-329. doi: 10.1016/j.wasman.2019.10. 036

Gold, M., Binggeli, M., Kurt, F., De Wouters, T., Reichlin, M., Zurbrügg, C., et al. (2020b). Novel experimental methods for the investigation of Hermetia illucens L. (Diptera: Stratiomyidae) larvae. J. Insect Sci. 20:21. doi: 10.1093/ jisesa/ieaa057

Gold, M., Egger, J., Scheidegger, A., Zurbrügg, C., Bruno, D., Bonelli, M., et al. (2020c). Estimating black soldier fly larvae biowaste conversion performance by simulation of midgut digestion. Waste Manag. 112, 40-51. doi: 10.1016/j. wasman.2020.05.026

Gold, M., Tomberlin, J. J. K., Diener, S., Zurbrügg, C., and Mathys, A. (2018). Decomposition of biowaste macronutrients, microbes, and chemicals in black soldier fly larval treatment: a review. Waste Manag. 82, 302-318. doi: 10.1016/ j.wasman.2018.10.022

Gupta, A. K., Nayduch, D., Verma, P., Shah, B., Ghate, H. V., Patole, M. S., et al. (2012). Phylogenetic characterization of bacteria in the gut of house flies (Musca domestica L.). FEMS Microbiol. Ecol. 79, 581-593. doi: 10.1111/j.1574-6941. 2011.01248.x

Gustavsson, J., Cederberg, C., Sonesson, U., van Otterdijk, R., and Meybeck, A. (2011). Global Food Losses and Food Waste: Extent, Causes and Prevention. Rome: FAO.

Hahn, T., Roth, A., Ji, R., Schmitt, E., and Zibek, S. (2019). Chitosan production with larval exoskeletons derived from the insect protein production. J. Biotechnol. 310, 62-67. doi: 10.1016/j.jbiotec.2019.12.015

Hieke, A. S. C., and Pillai, S. D. (2018). Escherichia coli cells exposed to lethal doses of electron beam irradiation retain their ability to propagate bacteriophages and are metabolically active. Front. Microbiol. 9:2138. doi: 10.3389/fmicb.2018. 02138

Holzapfel, W. H., Haberer, P., Geisen, R., Björkroth, J., and Schillinger, U. (2001). Taxonomy and important features of probiotic microorganisms in food and nutrition. Am. J. Clin. Nutr. 73, 365s-373s. doi: 10.1093/ajcn/73.2.365s

Hugerth, L. W., Wefer, H. A., Lundin, S., Jakobsson, H. E., Lindberg, M., Rodin, S., et al. (2014). DegePrime, a program for degenerate primer design for broadtaxonomic-range PCR in microbial ecology studies. Appl. Environ. Microbiol. 80, 5116-5123. doi: 10.1128/aem.01403-14

International Organization for Standardization (ISO) (2017). ISO 11137-3: Sterilization of Health Care Products. Radiation. Guidance on Dosimetric Aspects of Development, Validation and Routine Control. Geneva.

Janssen, R. H., Vincken, J. P., Van Den Broek, L. A. M., Fogliano, V., and Lakemond, C. M. M. (2017). Nitrogen-to-protein conversion factors for three edible insects: Tenebrio molitor, Alphitobius diaperinus, and Hermetia illucens. J. Agric. Food Chem. 65, 2275-2278. doi: 10.1021/acs.jafc.7b00471

Jeon, H., Park, S., Choi, J., Jeong, G., Lee, S. B., Choi, Y., et al. (2011). The intestinal bacterial community in the food waste-reducing larvae of Hermetia illucens. Curr. Microbiol. 62, 1390-1399. doi: 10.1007/s00284-011-9874-8 
Jiang, C. L., Jin, W. Z., Tao, X. H., Zhang, Q., Zhu, J., Feng, S. Y., et al. (2019). Black soldier fly larvae (Hermetia illucens) strengthen the metabolic function of food waste biodegradation by gut microbiome. Microb. Biotechnol. 12, 528-543. doi: 10.1111/1751-7915.13393

Klammsteiner, T., Walter, A., Bogataj, T., Heussler, C. D., Stres, B., Steiner, F. M., et al. (2020). The core gut microbiome of black soldier fly (Hermetia illucens) larvae raised on low-bioburden diets. Front. Microbiol. 11:993. doi: 10.3389/ fmicb.2020.00993

Lalander, C., Diener, S., Magri, M. E., Zurbruegg, C., Lindström, A., and Vinneras, B. (2013). Faecal sludge management with the larvae of the black soldier fly (Hermetia illucens) - from a hygiene aspect. Sci. Total Environ. 458-460, 312-318. doi: 10.1016/j.scitotenv.2013.04.033

Lalander, C., Diener, S., Zurbrügg, C., and Vinnerås, B. (2019). Effects of feedstock on larval development and process efficiency in waste treatment with black soldier fly (Hermetia illucens). J. Clean. Prod. 208, 211-219. doi: 10.1016/j. jclepro.2018.10.017

Lalander, C. H., Fidjeland, J., Diener, S., Eriksson, S., and Vinnerås, B. (2014). High waste-to-biomass conversion and efficient Salmonella spp. reduction using black soldier fly for waste recycling. Agron. Sustain. Dev. 35, 261-271. doi: 10.1007/s13593-014-0235-4

Lee, W.-J., and Brey, P. T. (2013). How microbiomes influence metazoan development:insights from history and Drosophila modeling of gut-microbe interactions. Annu. Rev. Cell Dev. Biol. 29, 571-592. doi: 10.1146/annurevcellbio-101512-122333

Lemos, L. N., Fulthorpe, R. R., Triplett, E. W., and Roesch, L. F. W. (2011). Rethinking microbial diversity analysis in the high throughput sequencing era. J. Microbiol. Methods 86, 42-51. doi: 10.1016/j.mimet.2011.03.014

Lerch, K., Linde, H. J., Lehn, N., and Grifka, J. (2003). Bacteria ingestion by blowfly larvae: an in vitro study. Dermatology 207, 362-366. doi: 10.1159/000074115

Li, Z., Lu, H., Ren, L., and He, L. (2013). Experimental and modeling approaches for food waste composting: a review. Chemosphere 93, 1247-1257. doi: 10.1016/ j.chemosphere.2013.06.064

Liu, C., Yao, H., Chapman, S. J., Su, J., and Wang, C. (2020). Changes in gut bacterial communities and the incidence of antibiotic resistance genes during degradation of antibiotics by black soldier fly larvae. Environ. Int. 142:105834. doi: 10.1016/j.envint.2020.105834

Ma, J., Lei, Y., Rehman, K. U., Yu, Z., Zhang, J., Li, W., et al. (2018). Dynamic effects of initial ph of substrate on biological growth and metamorphosis of black soldier fly (Diptera: Stratiomyidae). Environ. Entomol. 47, 159-165. doi: 10.1093/ee/nvx186

Ma, Q., Fonseca, A., Liu, W., Fields, A. T., Pimsler, M. L., Spindola, A. F., et al. (2012). Proteus mirabilis interkingdom swarming signals attract blow flies. ISME J. 6, 1356-1366. doi: 10.1038/ismej.2011.210

Magoč, T., and Salzberg, S. L. (2011). FLASH: fast length adjustment of short reads to improve genome assemblies. Bioinformatics 27, 2957-2963. doi: 10.1093/ bioinformatics/btr507

Manos, J. I. M., and Belas, R. (2006). The genera Proteus, Providencia, and Morganella. Prokaryotes 6, 245-269.

Mariotti, F., Tomé, D., and Mirand, P. P. (2008). Converting nitrogen into protein - Beyond 6.25 and Jones' factors. Crit. Rev. Food Sci. Nutr. 48, 177-184. doi: 10.1080/10408390701279749

Maturin, L., and Peeler, J. T. (2001). Bacteriological Analytical Manual: Aerobic Plate Count. Silver Spring MD: United States Food and Drug Administration.

Mazza, L., Xiao, X., ur Rehman, K., Cai, M., Zhang, D., Fasulo, S., et al. (2020). Management of chicken manure using black soldier fly (Diptera: Stratiomyidae) larvae assisted by companion bacteria. Waste Manag. 102, 312-318. doi: 10 . 1016/j.wasman.2019.10.055

McMurdie, P. J., and Holmes, S. (2013). Phyloseq: an R package for reproducible interactive analysis and graphics of microbiome census data. PLoS One 8:e61217. doi: 10.1371/journal.pone.0061217

Merrill, A. L. (1973). Energy Value of Foods. Darby, PA: DIANE Publisher.

Mertenat, A., Diener, S., and Zurbrügg, C. (2019). Black soldier fly biowaste treatment - assessment of global warming potential. Waste Manag. 84, 173-181. doi: 10.1016/j.wasman.2018.11.040

Michelou, V. K., Caporaso, J. G., Knight, R., and Palumbi, S. R. (2013). The ecology of microbial communities associated with Macrocystis pyrifera. PLoS One 8:e67480. doi: 10.1371/journal.pone.0067480
Mumcuoglu, K. Y., Miller, J., Mumcuoglu, M., Friger, M., and Tarshis, M. (2001). Destruction of bacteria in the digestive tract of the maggot of Lucilia sericata (Diptera: Calliphoridae). J. Med. Entomol. 38, 161-166. doi: 10.1603/00222585-38.2.161

Nyakeri, E. M., Ogola, H. J. O., Ayieko, M. A., and Amimo, F. A. (2017). Valorisation of organic waste material: growth performance of wild black soldier fly larvae (Hermetia illucens) reared on different organic wastes. J. Insects Food Feed 3, 193-202. doi: 10.3920/JIFF2017.0004

Oksanen, J. F., Blanchet, G., Friendly, M., Kindt, R., Legendre, P., McGlinn, D., et al. (2019). vegan: Community Ecology Package. R package version 2.5-6.

Pang, W., Hou, D., Chen, J., Nowar, E. E., Li, Z., Hu, R., et al. (2020). Reducing greenhouse gas emissions and enhancing carbon and nitrogen conversion in food wastes by the black soldier fly. J. Environ. Manage. 260:110066. doi: 10. 1016/j.jenvman.2020.110066

Papargyropoulou, E., Lozano, R., Steinberger, K., Wright, J., Ujang, N., and Bin, Z. (2014). The food waste hierarchy as a framework for the management of food surplus and food waste. J. Clean. Prod. 76, 106-115. doi: 10.1016/j.jclepro.2014. 04.020

Pimentel, A. C., Barroso, I. G., Ferreira, J. M. J., Dias, R. O., Ferreira, C., Terra, W. R., et al. (2018). Molecular machinery of starch digestion and glucose absorption along the midgut of Musca domestica. J. Insect Physiol. 109, 11-20. doi: 10.1016/j.jinsphys.2018.05.009

R Core Team (2020). R: A Language and Environment for Statistical Computing. Vienna: R Foundation for Statistical Computing.

Raimondi, S., Spampinato, G., Macavei, L. I., Lugli, L., Candeliere, F., Rossi, M., et al. (2020). Effect of rearing temperature on growth and microbiota composition of Hermetia illucens. Microorganisms 8:902. doi: 10.3390/ microorganisms 8060902

Rehman, K. U., Ur Rehman, R., Somroo, A. A., Cai, M., Zheng, L., Xiao, X., et al. (2019). Enhanced bioconversion of dairy and chicken manure by the interaction of exogenous bacteria and black soldier fly larvae. J. Environ. Manage. 237, 75-83. doi: 10.1016/j.jenvman.2019.02.048

Schmieder, R., and Edwards, R. (2011). Quality control and preprocessing of metagenomic datasets. Bioinformatics 27, 863-864. doi: 10.1093/ bioinformatics/btr026

Scully, E., Friesen, K., Wienhold, B., and Durso, L. M. (2017). Microbial communities associated with stable fly (Diptera: Muscidae) larvae and their developmental substrates. Ann. Entomol. Soc. Am. 110, 61-72. doi: 10.1093/ aesa/saw087

Shannon, C. E., and Weaver, W. (1949). The Mathematical Theory of Communication. Urbana IL: University of Illinois Press.

Shelomi, M., Wu, M.-K., Chen, S.-M., Huang, J.-J., and Burke, C. G. (2020). Microbes associated with black soldier fly (Diptera: Stratiomiidae) degradation of food waste. Environ. Entomol. 49, 405-411. doi: 10.1093/ee/nvz164

Shin, S. C., Kim, S. H., You, H., Kim, B., Kim, A. C., Lee, K. A., et al. (2016). Drosophila Microbiome modulates host developmental and metabolic homeostasis via insulin signaling. Nat. Microbiol. 334:16207. doi: 10.1016/j. gene.2011.11.060

Simpson, E. H. (1949). Measurement of diversity. Nature 163:688. doi: 10.1038/ 163688a0

Singh, B., Crippen, T. L., Zheng, L., Fields, A. T., Yu, Z., Ma, Q., et al. (2014). A metagenomic assessment of the bacteria associated with Lucilia sericata and Lucilia cuprina (Diptera: Calliphoridae). Appl. Microbiol. Biotechnol. 99, 869-883. doi: 10.1007/s00253-014-6115-7

Smetana, S., Palanisamy, M., Mathys, A., and Heinz, V. (2016). Sustainability of insect use for feed and food: life cycle assessment perspective. J. Clean. Prod. 137, 741-751. doi: 10.1016/j.jclepro.2016.07.148

Smetana, S., Schmitt, E., and Mathys, A. (2019). Sustainable use of Hermetia illucens insect biomass for feed and food: attributional and consequential life cycle assessment. Resour. Conserv. Recycl. 144, 285-296. doi: 10.1016/j. resconrec.2019.01.042

Somroo, A. A., ur Rehman, K., Zheng, L., Cai, M., Xiao, X., Hu, S., et al. (2019). Influence of Lactobacillus buchneri on soybean curd residue co-conversion by black soldier fly larvae (Hermetia illucens) for food and feedstock production. Waste Manag. 86, 114-122. doi: 10.1016/j.wasman.2019.01.022

Storelli, G., Defaye, A., Erkosar, B., Hols, P., Royet, J., and Leulier, F. (2011). Lactobacillus plantarum promotes Drosophila systemic growth by modulating 
hormonal signals through TOR-dependent nutrient sensing. Cell Metab. 14, 403-414. doi: 10.1016/j.cmet.2011.07.012

Storelli, G., Strigini, M., Grenier, T., Bozonnet, L., Schwarzer, M., Daniel, C., et al. (2018). Drosophila perpetuates nutritional mutualism by promoting the fitness of its intestinal symbiont Lactobacillus plantarum. Cell Metab. 27, 362-377. doi: 10.1016/j.cmet.2017.11.011

Su, Z., Zhang, M., Liu, X., Tong, L., Huang, Y., Li, G., et al. (2010). Comparison of bacterial diversity in wheat bran and in the gut of larvae and newly emerged adult of Musca domestica (Diptera: Muscidae) by use of ethidium monoazide reveals bacterial colonization. J. Econ. Entomol. 103, 1832-1841. doi: 10.1603/ EC10142

Tomberlin, J. K., Crippen, T. L., Tarone, A. M., Singh, B., Adams, K., Rezenom, Y. H., et al. (2012). Interkingdom responses of flies to bacteria mediated by fly physiology and bacterial quorum sensing. Anim. Behav. 84, 1449-1456. doi: 10.1016/j.anbehav.2012.09.013

Uriel, Y., Gries, R., Tu, L., Carroll, C., Zhai, H., Moore, M., et al. (2020). The fly factor phenomenon is mediated by interkingdom signaling between bacterial symbionts and their blow fly hosts. Insect Sci. 27, 256-265. doi: 10.1111/17447917.12632

Van der Fels-Klerx, H. J., Camenzuli, L., Belluco, S., Meijer, N., and Ricci, A. (2018). Food safety issues related to uses of insects for feeds and foods. Compr. Rev. Food Sci. Food Saf. 17, 1172-1183. doi: 10.1111/1541-4337.12385

Varelas, V. (2019). Food wastes as a potential new source for edible insect mass production for food and feed: a review. Fermentation 5:81. doi: 10.3390/ fermentation5030081

Vieco-Saiz, N., Belguesmia, Y., Raspoet, R., Auclair, E., Gancel, F., Kempf, I., et al. (2019). Benefits and inputs from lactic acid bacteria and their bacteriocins as alternatives to antibiotic growth promoters during food-animal production. Front. Microbiol. 10:57. doi: 10.3389/fmicb.2019.00057

Vogel, H., Müller, A., Heckel, D. G., Gutzeit, H., and Vilcinskas, A. (2018). Nutritional immunology: diversification and diet-dependent expression of antimicrobial peptides in the black soldier fly Hermetia illucens. Dev. Comp. Immunol. 78, 141-148. doi: 10.1016/j.dci.2017.09.008

Wang, Y.-S., and Shelomi, M. (2017). Review of black soldier fly (Hermetia illucens) as animal feed and human food. Foods 6:91. doi: 10.3390/foods6100091

Wu, G. (2016). Dietary protein intake and human health. Food Funct. 7, 1251-1265. doi: $10.1039 / \mathrm{c} 5$ fo $01530 \mathrm{~h}$

Wu, S., Xu, S., Chen, X., Sun, H., Hu, M., Bai, Z., et al. (2018). Bacterial communities changes during food waste spoilage. Sci. Rep. 8:8220.

Wynants, E., Crauwels, S., Verreth, C., Gianotten, N., Lievens, B., Claes, J., et al. (2018). Microbial dynamics during production of lesser mealworms (Alphitobius diaperinus) for human consumption at industrial scale. Food Microbiol. 70, 181-191. doi: 10.1016/j.fm.2017.09.012
Wynants, E., Frooninckx, L., Crauwels, S., Verreth, C., De Smet, J., Sandrock, C., et al. (2019). Assessing the microbiota of black soldier fly larvae (Hermetia illucens) reared on organic waste streams on four different locations at laboratory and large scale. Microb. Ecol. 77, 913-930. doi: 10.1007/s00248-018$1286-\mathrm{x}$

Xiao, X., Mazza, L., Yu, Y., Cai, M., Zheng, L., Tomberlin, J. K., et al. (2018). Efficient co-conversion process of chicken manure into protein feed and organic fertilizer by Hermetia illucens L. (Diptera: Stratiomyidae) larvae and functional bacteria. J. Environ. Manage. 217, 668-676. doi: 10.1016/j.jenvman.2018. 03.122

Yu, G., Cheng, P., Chen, Y., Li, Y., Yang, Z., Chen, Y., et al. (2011). Inoculating poultry manure with companion bacteria influences growth and development of black soldier fly (Diptera: Stratiomyidae) larvae. Environ. Entomol. 40, 30-35. doi: $10.1603 /$ en 10126

Zhan, S., Fang, G., Cai, M., Kou, Z., Xu, J., Cao, Y., et al. (2020). Genomic landscape and genetic manipulation of the black soldier fly Hermetia illucens, a natural waste recycler. Cell Res. 30, 50-60. doi: 10.1038/s41422-019-0252-6

Zhao, Y., Wang, W., Zhu, F., Wang, X., Wang, X., and Lei, C. (2017). The gut microbiota in larvae of the housefly Musca domestica and their horizontal transfer through feeding. AMB Express 7:147.

Zurbrügg, C., Dortmans, B., Fadhila, A., Verstappen, B., and Diener, S. (2018). From pilot to full scale operation of a waste-to-protein treatment facility. Detritus 1, 18-22.

Zurek, K., and Nayduch, D. (2016). Bacterial associations across house fly life history: evidence for transstadial carriage from managed manure. J. Insect Sci. 16, 2016-2019. doi: 10.1093/jisesa/ iev156

Zurek, L., Schal, C., and Watson, D. W. (2000). Diversity and contribution of the intestinal bacterial community to the development of Musca domestica (Diptera: Muscidae) larvae. J. Med. Entomol. 37, 924-928. doi: 10.1603/00222585-37.6.924

Conflict of Interest: The authors declare that the research was conducted in the absence of any commercial or financial relationships that could be construed as a potential conflict of interest.

Copyright (c) 2020 Gold, von Allmen, Zurbrügg, Zhang and Mathys. This is an open-access article distributed under the terms of the Creative Commons Attribution License (CC BY). The use, distribution or reproduction in other forums is permitted, provided the original author(s) and the copyright owner(s) are credited and that the original publication in this journal is cited, in accordance with accepted academic practice. No use, distribution or reproduction is permitted which does not comply with these terms. 